\title{
A novel bivalent DNA vaccine encoding both spike protein receptor-binding domain and nucleocapsid protein of SARS-CoV-2 to elicit $T$ cell and neutralising antibody responses that cross react with variants
}

Brentville $V A^{1}$, Vankemmelbeke $M^{1}$, Metheringham $R L^{1}$, Symonds $P^{1}$, Cook $K W^{1}$, Urbanowicz $R^{2,3,4,5}$, Tsoleridis $T^{2,3,4}$, Coleman $C^{4}$, Chang $K-C^{6}$, Skinner $A^{1}$, Dubinina $E^{1}$, Daniels $I^{1}$, Shah $S^{1}$, Dixon $\mathrm{JE}^{7}$, Pockley $\mathrm{AG}^{8}$, Adams $\mathrm{SE}^{9}$, Paston $S \mathrm{~J}^{1,9}$, Daly $\mathrm{JM}^{6}$, Ball $\mathrm{J}^{2,3,4}$ and Durrant $\mathrm{LG}^{1,10}$.

\section{Affiliations}

${ }^{1}$ Scancell Ltd, The University of Nottingham Biodiscovery Institute, Nottingham, UK

${ }^{2}$ Wolfson Centre for Global Virus Research, The University of Nottingham, Queen's Medical Centre, Derby Road, Nottingham, UK

${ }^{3} \mathrm{NIHR}$ Nottingham Biomedical Research Centre, Nottingham University Hospitals NHS Trust and the University of Nottingham; Queen's Medical Centre, Derby Road, Nottingham, UK

${ }^{4}$ School of Life Sciences, The University of Nottingham, Queen's Medical Centre, Derby Road, Nottingham, UK

${ }^{5}$ Department of Infection Biology and Microbiomes, Institute of Infection, Veterinary and Ecological Sciences, University of Liverpool, Liverpool, UK

${ }^{6}$ School of Veterinary Medicine and Science, University of Nottingham, Nottingham, UK.

${ }^{7}$ Division of Regenerative Medicine \& Cellular Therapies (RMCT), The University of Nottingham Biodiscovery Institute, School of Pharmacy, University Park, Nottingham, UK

${ }^{8}$ John van Geest Cancer Research Centre, School of Science and Technology, Nottingham Trent University, Clifton Campus, Nottingham, UK

${ }^{9}$ Scancell Ltd, John Eccles House, Robert Robinson Avenue, Oxford Science Park, Oxford, UK

${ }^{10}$ Division of Cancer and Stem Cells, The University of Nottingham Biodiscovery Institute, Nottingham UK

Corresponding Author: LG Durrant lindy.durrant@nottingham.ac.uk

Keywords: SARS-CoV-2, DNA vaccine, T cells, neutralising antibodies 


\section{Abstract}

The efficacy of vaccines targeting SARS-CoV-2 is becoming apparent now that the mRNA and adenovirus vector vaccines that have been approved for emergency use are showing promise. However, the longevity of the protective immune response and its efficacy against emerging variants remains to be determined. To improve longevity and future protection against variants, we have designed a DNA vaccine encoding both the SARS-CoV-2 spike $(\mathrm{S})$ protein receptor-binding domain (RBD) and its nucleocapsid $(\mathrm{N})$ protein, the latter of which is highly conserved amongst beta coronaviruses. The vaccine elicits strong proinflammatory CD4 Th1 and CD8 T-cell responses to both proteins, with these responses being significantly enhanced by fusing the nucleocapsid sequence to a modified Fc domain. We have shown that the vaccine also stimulates high titre antibody responses to RBD which efficiently neutralise in both a pseudotype and live virus neutralisation assay and show cross reactivity with $S$ proteins from the emerging variants Alpha (B.1.1.7) and Beta (B.1.351). This DNA platform can be easily adapted to target variant RBD and N proteins and we show that a vaccine variant encoding the B.1.351 RBD sequence stimulates cross-reactive humoral and T-cell immunity. These data support the translation of this DNA vaccine platform into the clinic, thereby offering a particular advantage for targeting emerging SARSCoV-2 variants.

\section{Introduction}

The current SARS-CoV-2 pandemic has prompted a global response with researchers from hundreds of institutions across the world developing and testing potential vaccine candidates that can prevent infection and COVID-19 disease. SARS-CoV-2 is known to facilitate host cell entry by targeting the cellular receptor, ACE2 using its densely-glycosylated spike (S) protein. The $S$ protein is a trimeric class I fusion protein which undergoes several structural rearrangements and cleavage events to eventually fuse the viral and host membranes [1, 2], a process triggered by S1 subunit binding to the host cell receptor ACE2 via its receptor binding domain (RBD). The virus targets the airway epithelial cells, alveolar epithelial cells, vascular endothelial cells and macrophages in the lung, all of which express ACE2 [3, 4]. Viral assembly inside the host cell requires four structural proteins, the $S$, matrix $(M)$, envelope $(E)$, and nucleocapsid $(N)$ proteins. Homotrimers of the $S$ protein make up the receptor-binding spikes on the viral surface $[5,6]$. The $N$ protein contains two domains that each bind the viral genome, packaging it into virions [11-13]. SARS-CoV-2 has a singlestranded positive sense RNA genome and the coronavirus family have the largest genomes 
in this category of viruses, encoding RNA processing and editing enzymes which increase the fidelity of replication. However, variation arises through a high rate of homologous recombination. Although SARS-CoV-2 can cause severe symptoms and death in the elderly or clinically vulnerable populations, the fact that approximately $80 \%$ of infected individuals present with no symptoms or mild infection [14] suggests that effective immunity can control the infection.

As the $S$ protein has been shown to be the primary target for neutralising antibodies in patients with SARS-CoV-2 [15], it has been the focus of most vaccine development programmes. Although, the $S$ protein is also a key target for $T$ cell responses, responses have also been detected against the $\mathrm{M}, \mathrm{E}$ and $\mathrm{N}$ proteins and several other non-structural proteins [16]. The currently approved SARS-CoV-2 vaccines and most of those under development predominantly aim to stimulate neutralising antibody responses against the $S$ protein to block the virus binding to ACE2 receptor and entering cells. However, viral evolution has created numerous mutations in the $S$ protein that not only have increased infectivity but have also reduced the efficacy of neutralising antibodies that have been raised to previously encountered viruses [17-20]. The $\mathrm{N}$ protein plays a vital role in viral RNA replication and the formation of new virions and is therefore highly conserved between coronaviruses [4, 21]. It is present in large quantities and can stimulate a strong immune response. Critically, most survivors of SARS-CoV-2 show evidence of T cell and antibody immunity against the $\mathrm{N}$ protein [22], suggesting that it is a target of the natural immune response. Our vaccine design includes the $\mathrm{N}$ protein in order to provide broader immunity during the ongoing viral pandemic, a strategy also being considered by other next generation vaccine developers [23].

We have previously shown that delivery of epitopes from tumour antigens, linked to human immunoglobulin G1 (IgG1) fragment crystallisable (Fc) in a DNA vector, stimulates high avidity CD8 T cell responses that are efficiently recruited into the memory pool [24-26]. The DNA vector enables direct presentation of the encoded epitopes in antigen presenting cells (APCs) as well as cross presentation of secreted Fc-fused proteins to dendritic cells via high affinity FcyR1 receptor (CD64) binding. This DNA vaccine platform has been successfully used in the clinic as a cancer immunotherapeutic, where it has shown to induce vaccinespecific T-cell responses in patients with melanoma and was compatible with a prime and multiple boosts dosing regimen [27]. Additionally, we have recently described an Fcengineering approach which increases the functional avidity of antibody target binding by enhancing Fc:Fc cooperativity [28] and this modified Fc forms part of our vaccine design. Herein, we describe the validation of this versatile and rapid to manufacture DNA platform 
for the generation of a SARS-CoV-2 vaccine targeting both the $\mathrm{N}$ protein and the S RBD . We report that the linkage of the $\mathrm{N}$ protein to the modified Fc enhances $\mathrm{T}$ cell immunity, and show that the inclusion of this N-modified Fc fusion alongside the RBD antigen in a bivalent DNA vector stimulates strong cellular and humoral immunity to both antigens. High titre antibody responses that exhibited pseudotype neutralisation with a $50 \%$ reduction in infective dose $\left(\mathrm{ID}_{50}\right)$ of $>5000$ were induced. High frequency CD8 and Th1 CD4 T cell responses to both RBD and $\mathrm{N}$ proteins were stimulated. Finally, we demonstrate the induction of variant cross-reactive immune responses and the flexibility of this DNA platform for targeting SARS-CoV-2 variants. Collectively, these results underpin the advancement of this DNA vector encoding RBD and modified Fc-linked N protein into clinical trials.

\section{Methods}

\section{DNA plasmids}

The backbone of the vaccine plasmids was derived from the FDA regulatory compliant vector backbone of pVAX1 (Invitrogen) for use in humans. All nucleotide sections for insertion were codon optimised for expression in humans and contain a human lgH leader (MDWIWRILFLVGAATGAHS). Codon-optimised nucleotide sections encoding the leader, amino acids (aa) of the S glycoprotein RBD domain 319-541 or 330-525 (GenBank accession number YP_009724390, isolate Wuhan-Hu-1) alone, fused in frame with either the Hinge- $\mathrm{CH} 2-\mathrm{CH} 3$ domain of the human IgG1 Fc constant region (GenBank accession number P01857) or the variant Hinge-CH2-CH3 iV1 (where 23 amino acids (aa) have been replaced with murine lgG3 residues) or attached to a fibritin trimer fold on (GYIPEAPRDGQAYVRKDGEWVLLSTFL) or disulphide bridge motif (CCGGGSG) via a glycine serine linker were synthesised with $\mathrm{BamHl}$ and $\mathrm{Xhol}$ sites inserted at the $5^{\prime}$ and 3 'ends respectively. In the first round of cloning, these sections were inserted into the $\mathrm{BamH} / \mathrm{Xhol}$ sites of the pVaxDCIB68 (SCIB1) plasmid as described previously [24, 29], in direct replacement of the SCIB1 light kappa chain in the first expression cassette to generate intermediate plasmids.

In a second round of cloning codon-optimised nucleotide sections encoding the leader, fulllength nucleoprotein aa 2-419 (Accession number YP_009724397) alone or fused in frame with the Hinge- $\mathrm{CH} 2-\mathrm{CH} 3$ domain of the human IgG1 constant domain or the variant Hinge$\mathrm{CH} 2-\mathrm{CH} 3 \mathrm{iV} 1$ were synthesised and flanked with Hindll/Pstl. The heavy chain was excised using Hindll/Pstl from the intermediate vectors generated from the first round and replaced with the $\mathrm{N}$ protein sections in the second expression cassette alongside the appropriate $\mathrm{S}$ section (Figure 1A). The sequences of both chains within each expression cassette of the pVaxDC vectors were confirmed by the dideoxy chain termination method [30]. 
The plasmid pCMV3-2019-nCoV-Spike (S1+S2)-long encodes full-length spike from SARSCoV-2 amino acid 1-1273 (GenBank accession number YP_009724390 /QHD43416.1) was obtained from Sino Biological (catalogue number VG40589-UT). This contained codon optimised cDNA for expression of the protein in mammalian cells inserted into the $\mathrm{Kpnl} / \mathrm{Xbal}$ sites of the mammalian expression vector pCMV3-untagged under control of the high-level expression mammalian human enhanced cytomegalovirus (CMV) immediate early promoter.

\section{Transient Expi293FTM transfection}

Secretion levels from plasmid DNA constructs were evaluated following transient transfections of Expi293FTM cells using the ExpiFectamine ${ }^{\mathrm{TM}} 293$ Transfection kit (Gibco, LifeTechnologies). Briefly, Expi293F ${ }^{\mathrm{TM}}$ cells in suspension $\left(100 \mathrm{~mL}, 2 \times 10^{6} / \mathrm{mL}\right)$ were transfected with $100 \mu \mathrm{g}$ DNA and conditioned medium harvested at day 6 post-transfection. Conditioned supernatant was filtered through $0.22 \mu \mathrm{m}$ bottle top filters (Merck Millipore) and sodium azide added to a final concentration of $0.2 \%(\mathrm{w} / \mathrm{v})$. Cell pellets were stored at $-80^{\circ} \mathrm{C}$. Cell lysates (intracellular RBD and N protein) were generated by processing the cell pellets in a suitable volume of RIPA buffer (Sigma Aldrich R0278) according to the manufacturer's recommendations.

Sandwich ELISA for detection of secreted and intracellular RBD and N protein Commercial kits/antibody pairs were used in both cases. $N$ protein was detected using the SARS-CoV-2 NP ELISA kit from Bioss, (cat\# BSKV0001) according to the supplier's instructions. Quantitation relied on the standard curve generated using the NP standard supplied with the kit. RBD was detected using a sandwich ELISA consisting of a capture antibody (SARS-CoV-2 S neutralising mouse monoclonal antibody (mAb) Sino Biological, 40591-MM43) combined with an HRPO-labelled detection antibody from the SARS-CoV-2 spike RBD Antibody Pair (Epigentek A73682). Capture antibody was coated at $200 \mathrm{ng} / \mathrm{well}$ and detection antibody was used at a dilution of 1:1000.

\section{Peptides and proteins}

Peptides were selected based on immune epitope database (IEDB) (http://www.iedb.org/) binding predictions [31] and from reports in the literature. Peptides (Table S1) were synthesised at $>90 \%$ purity (GenScript), stored lyophilised at $-80^{\circ} \mathrm{C}$ and then reconstituted in phosphate buffered saline (PBS) on day of use. SARS-CoV-2 RBD and N protein peptide pools were purchased from JPT Peptide Technologies and GenScript, respectively. SARSCoV-2 N and S1 proteins were obtained from Genscript and Sino Biological. 


\section{Animals and immunisation protocol}

Animal experiments were carried out with ethical approval under a UK Home Officeapproved Project License. HLA-A2.1+/+ HLADP4+/+ hCD4+/+ (HHDII/DP4; EM:02221, European Mouse Mutant Archive), HLA-A2/DR1 (HHDII/DR1; Pasteur Institute), HLA-A2 (HHDII; Pasteur Institute) transgenic mice or BALB/c and C57BI/6 (Charles River) aged 7-12 weeks were used.

Mice were immunised with $1 \mu \mathrm{g}$ plasmid DNA, coated onto gold particles, intradermally using a Helios $^{\mathrm{TM}}$ gene gun (BioRad, Hemel Hempstead, UK) on days 1, 8 and 15 and responses analysed on day 21 , unless stated otherwise.

\section{ELISpot assays}

Murine ELISpot kits (Mabtech) were used with $5 \times 10^{5}$ splenocytes/well in RPMI with Lglutamine, $10 \%(\mathrm{v} / \mathrm{v})$ foetal bovine serum (FCS) supplemented with penicillin, streptomycin, HEPES and $10^{-5} \mathrm{M} 2-\beta$ mercaptoethanol (Invitrogen). Synthetic peptide (5 $\mu \mathrm{g} / \mathrm{mL}$ ) or peptide pool $(1 \mathrm{ug} / \mathrm{mL})$ were added to triplicate wells. CD8, or CD4 mAbs were added for blocking studies $(20 \mu \mathrm{g} / \mathrm{mL})$. Plates were incubated at $37^{\circ} \mathrm{C}$ for 40 hours in an atmosphere of $5 \%$ $(\mathrm{v} / \mathrm{v}) \mathrm{CO}_{2}$. Spots were counted using an automated plate reader (Cellular Technologies Ltd).

Intracellular cytokine analysis

Splenocytes $\left(5 \times 10^{6} / \mathrm{mL}\right)$ were incubated with $5 \mu \mathrm{g} / \mathrm{mL}$ synthetic peptide or $0.5 \mu \mathrm{g} / \mathrm{mL}$ whole recombinant protein for 7 days. Cells were washed, plated at $5 \times 10^{6} / \mathrm{ml}$ and stimulated for $8-$ $12 \mathrm{hr}$ with medium alone, $0.25 \mu \mathrm{g} / \mathrm{mL}$ CD3 mAb (Thermofisher) as a positive control, $5 \mu \mathrm{g} / \mathrm{ml}$ synthetic peptide or $1 \mu \mathrm{g} / \mathrm{mL}$ peptide pool. Cells were incubated at $37^{\circ} \mathrm{C}$ for $8 \mathrm{hr}$ with Brefeldin A (BD Biosciences) and Monensin (Thermofisher) being added for the last $7 \mathrm{hr}$ of incubation. After $8 \mathrm{hr}$ incubation, cells were held at $4^{\circ} \mathrm{C}$ until staining. Cells were then washed and stained with APC efluor780 conjugated anti-mouse CD4 and Viogreen ${ }^{\mathrm{TM}}$ conjugated anti-mouse CD8 mAbs. Cells were subsequently washed, fixed and permeabilised using intracellular fixation/permeabilisation buffers (ThermoFisher). Intracellular antibody staining was performed in permeabilisation buffer for 30 min before washing and fixing. Stained samples were analysed using a Milteny Biotech MACSQuant ${ }^{\mathrm{TM}}$ 10 flow cytometer. Full details of the mAbs used are provided in Table S2.

\section{ELISA for $\mathrm{N}$ and $\mathrm{S} 1$ specific antibodies}

Blood collected from mice was allowed to clot for at least $30 \mathrm{~min}$ at room temperature, centrifuged at $1000 \mathrm{~g}$ for $10 \mathrm{~min}$ and serum collected. Serum from naïve mice was used as a control. Sera were diluted in $2 \%(\mathrm{w} / \mathrm{v})$ bovine serum albumin in PBS (BSA-PBS) and incubated for $1 \mathrm{hr}$ at room temperature (RT) in coated (S1 antigen, GenScript \#Z03501 or 
Sino Biological and N-protein, GenScript \#Z03488, both at $200 \mathrm{ng} /$ well) and blocked ELISA plates. Antibody binding to $\mathrm{S} 1$ antigen was detected using a three-step approach consisting of anti-mouse Fc biotin (Sigma Aldrich B7401) followed by streptavidin-HRPO (Life Technologies SA1007) and finally TMB (3,3', 5, 5' - tetramethylbenzidine) Core+ reagent (Bio-Rad BUF062C) for development. Antibody binding to $\mathrm{N}$ protein was detected using conventional two-step ELISA with an HRPO-conjugated anti-mouse Fc antibody (Sigma Aldrich A9309). All assays included a standard curve of mouse neutralising S1 antibody and mouse anti-N antibody (Sino Biological). Standard curves were used to extrapolate the amount $(\mu \mathrm{g} / \mathrm{mL})$ of specific immunoglobulin $(\mathrm{lg})$ in the sera samples.

\section{Pseudotype neutralisation assay}

SARS-CoV-2 S protein plasmids were generated and cloned, and pseudoparticles generated as previously described [32, 33]. Briefly, $1.5 \times 10^{6}$ HEK293T cells were seeded overnight in a $10 \mathrm{~cm}$ diameter Primaria-coated dish (Corning). Transfections were performed with $2 \mu \mathrm{g}$ each of the murine leukemia virus (MLV) Gag-Pol packaging vector (phCMV-5349), luciferase encoding reporter plasmid (pTG126) and plasmid encoding Wuhan strain SARS-CoV-2 spike using $24 \mu \mathrm{L}$ polyethylenimine (Polysciences) in Optimem (Gibco). Reaction mixtures were replaced with Complete DMEM after 6 hr. A no-envelope control (empty pseudotype) was used as a negative control in all experiments. Supernatants containing SARS-CoV-2 pseudotype viruses (pv) were harvested at $72 \mathrm{hr}$ post-transfection and filtered through $0.45 \mu \mathrm{m}$ membranes. Pseudotypes generated in the absence of the spike were used as a negative control. For infectivity and neutralisation testing of SARSCoV-2 pseudoparticles, $1 \times 10^{5}$ VeroE6 cells were seeded on white 96-well tissue culture plates (Corning) and incubated overnight at $37^{\circ} \mathrm{C}$. The following day, SARS-CoV-2 pseudotypes were mixed with appropriate amounts of heat inactivated serially diluted sera and then incubated for $1 \mathrm{hr}$ at RT before adding to cells. After $72 \mathrm{hrs}$ at $37^{\circ} \mathrm{C}$, cells were lysed with cell lysis buffer (cat no. E1500; Promega) and placed on a rocker for 15 min. Luciferase activity was then measured in relative light units (RLUs) using a FLUOstar Omega plate reader (BMG Labtech) and MARSdata analysis software. Each sample was tested in triplicate. Neutralising activities were reported as reciprocal serum dilution levels corresponding to $50 \%$ inhibitory dilution $\left(\mathrm{ID}_{50}\right)$ values and were calculated by nonlinear regression (GraphPad Prism version 9.1.2), using lower and upper bounds ( $0 \%$ and $100 \%$ inhibition) as constraints to assist curve fitting.

Live virus neutralisation assay

SARS-CoV-2 infectious virus (CVR-GLA-1) was obtained from the National was obtained from the Centre For AIDS Reagents, NIBSC, UK. 
Live virus neutralisation assays were performed using method previously described [34], except that $790 \mathrm{TCID}_{50} / \mathrm{ml}$ of the SARS-CoV-2 virus was added to each serum dilution. Additionally, for some experiments, the sera were diluted down to 1:81,920.

ACE2 binding inhibition assay

A V-PLEX COVID-19 ACE2 neutralisation kit from Meso Scale Diagnostics LLC was used to investigate the ability of vaccine-elicited antibodies to block the binding of ACE2 to RBD or whole S proteins. V-plex SARS-CoV-2 Panel 7 multispot plates containing S1 RBD and whole S proteins from Lineage A (originally identified in Wuhan) and variant (B1.1.7/Alpha, B1.351/Beta, P.1/Gamma) SARS-CoV-2 strains were blocked, followed by incubation with sera at 1:100 dilution and Sulfo-tagged human ACE2 protein, according to the manufacturer's instructions. Results are expressed as percentage inhibition of ACE2 binding via comparison of sera-incubated samples to diluent-containing wells (absence of inhibition).

\section{Statistical analysis}

Statistical analysis was performed using GraphPad Prism software version 9. Comparative analysis of the ELISpot results was performed by applying paired or unpaired ANOVA as appropriate with Sidak's multiple comparisons test and $\mathrm{P}$ values calculated accordingly. $\mathrm{P}<0.05$ values were considered statistically significant.

\section{Results}

Design and characterisation of DNA constructs

Spike RBD and $\mathrm{N}$ protein DNA sequences were obtained from the Lineage A SARS-CoV-2 variant and engineered alongside $\mathrm{N}$ terminal human $\mathrm{IgH}$ leader sequences into the pVAX1 vector backbone. Short (aa330-525) or long (aa319-541) S protein RBD sequences were fused in frame with human IgG1 Fc constant region, a fibritin timer domain or disulphide bridge motif (Figure 1A). N protein sequences were added alongside the $S$ protein RBD sequences, alone or fused in frame with human IgG1 $F c(F c)$ constant region or a modified human IgG1 Fc (Fc iV1) constant region (Figure 1A).

Expression of both $\mathrm{N}$ protein and RBD from DNA constructs was assessed by transfection of Expi293 ${ }^{\mathrm{TM}}$ cells followed by analysis of supernatant and cell lysate samples by sandwich ELISA. Constructs expressing the RBD region as a monomer or linked to Fc showed the highest levels of RBD protein secretion by Expi293 $\mathrm{F}^{\mathrm{TM}}$ cells, whereas those containing the long RBD trimer or shorter RBD trimer versions exhibited lower protein secretion levels 
(Figure $1 \mathrm{Bi}$ ). No significant difference was seen between the trimer variants (Supplementary Figure 1). The $\mathrm{N}$ protein secretion levels were overall much lower than the RBD secretion, with the $\mathrm{N}$ protein producing more secreted protein than the Fc and Fc iV1 $\mathrm{N}$ protein constructs (Figure 1Bii). Unlike antibody responses, the stimulation of a $\mathrm{T}$ cell response is not reliant on secreted protein, because of which protein was also measured in cell lysates to determine if protein was made but not secreted. Cells transfected with the construct expressing the RBD monomer showed the highest level of RBD protein in the cell lysates (Figure $1 \mathrm{Ci}$ ). A similar observation was seen for the $\mathrm{N}$ protein with highest levels in the cell lysate transfected with the construct expressing the non-fused $\mathrm{N}$ protein (Figure 1Cii). Collectively, the results suggest that functional RBD and $N$ protein are produced as both secreted and intracellular forms, which can stimulate both T-cell and antibody responses.

Linkage of $\mathrm{N}$ protein to modified Fc stimulates superior $\mathrm{N}$ specific $\mathrm{T}$ cell responses

$\mathrm{T}$ cell responses in mice following immunisations with vaccine constructs containing the $\mathrm{N}$ monomer, monomer linked to Fc or modified Fc (iV1) were evaluated using RBD and N protein overlapping peptide pools. Peptide pools contain 15aa peptides that overlap by 11 aa and span the entire sequence and stimulate both CD4 and CD8 T cell responses without requiring any prior knowledge of the presenting $\mathrm{MHC}$ allele. Splenocytes were isolated from mice 7 days after the last immunisation and T cell responses were assessed ex vivo by IFNy ELISpot following stimulation. In addition to the peptide pools, several peptides were selected from published reports and using prediction algorithms that were known or suggested to bind to HLA-A2 or murine $\mathrm{H}-2 \mathrm{~Kb} / \mathrm{d}, \mathrm{H}-2 \mathrm{Db} / \mathrm{d}$, I-Ab or I-Ad/Ed (Table S1).

A high frequency of $\mathrm{T}$ cells specific to the $\mathrm{N}$ protein was detected in mice immunised with DNA constructs containing the $\mathrm{N}$ protein linked to modified Fc (iV1) when compared to constructs containing $\mathrm{N}$ protein $(p=0.0278)$ or the $\mathrm{N}$ protein linked to unmodified Fc (Figure $2 \mathrm{Ai})$. A high frequency of $\mathrm{T}$ cells recognising the $\mathrm{N}$ 138-146 peptide was induced in HLA-A2 transgenic mice following immunisation with the DNA construct containing the $\mathrm{N}$ protein linked to a modified Fc (iV1) when compared to the frequency observed in mice immunised with the constructs containing $N$ protein alone $(p=0.0150)$ or linked to Fc $(p=0.0161)$ (Figure 2Aii). One peptide, conserved between SARS-CoV and SARS-CoV-2 [35], stimulated a response in cells from immunised HLA-A2 transgenic mice (N 138-146), thereby highlighting the potential of these $T$ cells to recognise other coronaviruses.

A high frequency of $T$ cells specific to the RBD antigen was detected in mice immunised with the vaccine constructs. The construct containing the RBD monomer induced a higher frequency of $T$ cells specific for the RBD protein when compared to the frequency of 
responses induced by a DNA construct containing the whole $S$ protein $(p=0.0002)$ (Figure 2B).

T-cell responses were further evaluated in BALB/c, C57BI/6 and HLA-A2 transgenic mice following immunisation with the DNA construct expressing RBD alongside $N$ linked to modified Fc (iV1) (also known as SN15) using RBD and N peptide pools and individual peptides. A high frequency of T cells specific for SARS-CoV-2 $\mathrm{N}$ and RBD were detected in all strains of mice. T cell responses to two longer peptides (RBD 505-524 and N 80-100) in addition to the RBD and $N$ peptide pools were seen in BALB/c mice $(p=0.0012, p=0.0171$, $p=0.0001$ and $p=0.0368$, respectively) (Figure 3A). Immunised C57BI/6 mice also exhibited T cell responses to the RBD 505-524 peptide and lower frequency responses, that did not reach significance to the N 212-231 and N 101-121 peptides (Figure 3B). T cell responses to the two short peptides RBD 417-425 ( $p<0.0001)$ and N 138-146 $(p<0.0001)$ peptides were detected in immunised HLA-A2 transgenic mice (Figure $3 C$ ), these peptides have been described as potential HLA-A2 epitopes in human studies [35, 36]. To confirm these to be CD8 peptides, the $T$ cell responses were assessed in the presence of CD4 or CD8 blocking antibodies (Figure 3D). The presence of the CD8 blocking antibody totally abrogated both responses $(p<0.0001)$ whereas the CD4 blocking antibody had little effect, thus confirming that these were CD8 responses in HLA-A2 transgenic mice.

To characterise the $T$ cell responses to the longer peptides which have the potential to contain both CD8 and CD4 epitopes, BALB/c mice were immunised with DNA constructs expressing RBD alongside $\mathrm{N}$ linked to modified Fc (iV1) and T cell responses to the N 80100 and RBD 505-524 peptides monitored by IFNy ELISpot assay in the presence of CD4 or CD8 blocking antibodies. A strong $T$ cell response to the $\mathrm{N}$ 80-100 peptide was observed and this was efficiently blocked by the CD4 antibody ( $p=0.0009)$ but not the CD8 antibody, implying the presence of a CD4 epitope within this peptide sequence (Figure 3Eii). Although a strong $T$ cell response to the RBD 505-524 peptide was observed this was not significantly inhibited by either the CD4 or CD8 blocking antibodies, suggesting that this peptide sequence stimulates both CD4 and CD8 responses (Figure 3Ei).

The $\mathrm{T}$ cell responses to the RBD and $\mathrm{N}$ peptide pools were examined by intracellular cytokine staining using splenocytes from BALB/C and C57BI/6 mice immunised with the DNA construct expressing RBD alongside $\mathrm{N}$ linked to modified Fc (iV1). This enabled both the confirmation of CD4 or CD8 mediated responses as well as analysis of the cytokine profile of the responses. To determine the presence of CD4 $\mathrm{T}$ cell responses to the vaccine, splenocytes from immunised BALB/C mice expanded in vitro with recombinant $\mathrm{S} 1$ and $\mathrm{N}$ 
protein were restimulated with either RBD or N peptide pools and analysed for expression of IFNy, TNFa and IL10. A population of CD4 positive and CD4 negative T cells produced IFNy and TNFa in response to restimulation with the RBD peptide pool (Figure 4A) suggesting the likely presence of both CD4 and potentially CD8 responses specific to RBD. Only CD4 positive T cells produced IFNy and TNFa in response to stimulation with the $\mathrm{N}$ peptide pool. No cytokines were produced by the CD4 negative T cells suggesting CD4 responses to the $\mathrm{N}$ protein which is consistent with the ELISpot data (Figure 4A). There was no evidence of any IL-10 responses.

Responses of splenocytes from the BALB/c mice in the ELISpot and intracellular cytokine analysis to the RBD peptide pool and the RBD 505-524 peptide were anticipated to be both CD4 and CD8 mediated. To confirm this, splenocytes from immunised BALB/c mice were expanded in vitro with RBD 505-524 peptide and examined by intracellular cytokine staining. The response to the RBD 505-524 peptide was predominantly CD8 cells making both IFNy and TNFa but no IL-10 (Figure 4B). However, a small response in the CD4 population was also observed thus providing evidence that this peptide contains both CD4 and CD8 epitopes and confirming both CD4 and CD8 RBD specific responses are generated by this vaccine construct.

In addition to the responses in the BALB/C model, responses to the $N$ and RBD proteins were further characterised in $\mathrm{C} 57 \mathrm{BI} / 6$ mice. For this, splenocytes from immunised $\mathrm{C} 57 \mathrm{BI} / 6$ mice were also expanded in vitro with $\mathrm{S} 1$ or $\mathrm{N}$ proteins and analysed for specific responses by intracellular cytokine staining. Figure $4 \mathrm{C}$ shows IFNY and TNFa responses to the $\mathrm{N}$ peptide pool among both CD4 and CD8 T-cell populations. No evidence of IL-10 or IL-4 responses was observed indicating that the CD4 cells exhibited a Th1 phenotype. Low frequency CD4 and CD8 responses were also stimulated using the N 101-121 peptide in this model (Figure 4C). Analysis of splenocytes from $\mathrm{C} 57 \mathrm{BI} / 6$ vaccinated mice also demonstrate an expansion of both CD4 and CD8 T cells that respond to the RBD 505-524 peptide. These responses display an IFNy and TNFa phenotype, with no evidence of IL-10 or IL-4 responses (Figure $4 \mathrm{C}$ ). These data provide further evidence in a second HLA mouse model that CD4 and CD8 T cell responses can be stimulated by vaccination to both the $\mathrm{N}$ and RBD proteins.

DNA vaccination stimulates strong anti-N and anti-RBD binding antibody responses that show efficient pseudotype neutralisation

Humoral responses were evaluated in sera from immunised BALB/c mice immunised with constructs containing the RBD monomer, whole $S$, trimer or monomer linked to Fc and analysed for reactivity to SARS-CoV-2 S1 protein by ELISA. (Figure 5Ai and ii). Vaccination 
induced potent antibody responses to the $\mathrm{S} 1$ protein which were detectable in sera from all constructs at up to 1 in 100,000 dilution. Constructs containing the RBD monomer and RBD linked to Fc showed the highest $\mathrm{EC}_{50}$ and quantity of $\mathrm{lg}$ with approximately $50 \mu \mathrm{g} / \mathrm{mL}$ anti-S1 Ig being detected.

The generation of a potent antibody response capable of inhibiting the binding of the $S$ protein to ACE2 receptor and subsequent viral infection is vital for an effective SARS-CoV-2 vaccine. The ability of sera from mice immunised with the DNA constructs containing RBD monomer, trimer or monomer linked to Fc to prevent viral infection was therefore tested in a pseudotype neutralisation assay. For this, sera from mice immunised with the RBD monomer showed higher neutralisation $\mathrm{IC}_{50}$ values (Figure $5 \mathrm{Bi}$-ii) with $50 \%$ neutralisation at serum dilutions of greater than 1in 5000, higher than that seen with the NIBSC 20/136 international antibody standard. Sera from mice immunised with the RBD monomer DNA construct showed higher $\mathrm{IC}_{50}$ neutralisation values compared to that from mice immunised with the DNA expressing the whole $S$ (Figure $5 \mathrm{C}$ ). This is also evident from the differing antibody levels shown in Figure 5Aii where the RBD monomer generated high $\mathrm{EC}_{50}$ values when compared to the construct expressing full-length $S$ antigen.

Sera were also analysed for reactivity to SARS-CoV-2 N protein by ELISA. Lower antibody responses were seen to the $N$ protein than to the $R D$, with similar $E_{50}$ values obtained for all constructs irrespective of whether the N protein was fused to Fc or not (Figure 5D).

\section{Responses induced by DNA vaccination show variant cross reactivity}

Emerging SARS-CoV-2 variants are a major cause for concern as they have the potential for greater infectivity and increased disease severity. As variants of SARS-CoV-2 have the potential to impact the efficacy of the current vaccines approved for emergency use that were generated using the original Lineage $A$ virus, there remains doubt about the effectiveness of current vaccines based on this isolate against these new variants. We therefore examined the ability of sera from BALB/c mice immunised with the DNA vaccine expressing RBD alongside $\mathrm{N}$ linked to modified Fc (iV1) (also known as SN15) for reactivity to the Lineage A SARS-CoV-2 S1 protein as well S1 proteins incorporating the mutations seen in the B.1.1.7 (Alpha) and B.1.351 (Beta) variants by ELISA. Vaccination induced a potent antibody response with reactivity to all the $S 1$ proteins detectable in sera at up to a 1 in 100,000 dilution (Figure 6A). However, in line with other reports, we also observed a significant $(p<0.0001)$ reduction in reactivity to the B.1.351 (Beta) variant $S 1$ protein compared to the Lineage A protein, whereas reactivity to the B.1.1.7 (Alpha) variant S1 protein was not significantly reduced. 
One of the most concerning variants of concern (VoC) currently in circulation is B.1.351 (Beta). Recent data have suggested that although the approved vaccines induce responses that can provide some cross-reactivity with the B.1.1.7 (Alpha) variant, they are less effective against the B.1.351 (Beta) and P.1 (Gamma) variants [37-39]. To address this, we engineered a new construct encoding the RBD protein containing the mutations within the B.1.351 (Beta) variant alongside $\mathrm{N}$ linked to modified Fc (iV1) (also known as SN17). Sera from mice immunised with the original DNA vaccine construct, the B.1.351 (Beta) vaccine construct or the construct expressing the whole $S$ antigen from the original variant were analysed for reactivity to the original Lineage A SARS-CoV-2 S1 protein as well S1 protein incorporating the mutations seen in the B.1.351 (Beta) variant by ELISA. Substantial antibody responses were observed to the protein variants up to 1 in 100,000 dilution (Figure $6 \mathrm{~B})$. As noted above, sera raised against the original Lineage $A$ vaccine exhibited a decrease in reactivity to the B.1.351 (Beta) variant S1 protein compared to the Lineage A S1 protein with the $\mathrm{EC}_{50}$ decreasing from 4664 to 2949 . The responses induced by the B.1.351 (Beta) variant vaccine generated higher titres to the B.1.351 (Beta) variant $\mathrm{S} 1$ protein $\left(\mathrm{EC}_{50}\right.$ of 3931) with lower titres against the original Lineage A S1 protein ( $E C_{50}$ of 2086). The variant vaccines induced higher titres to both the original Lineage A S1 and B.1.351 (Beta) S1 proteins compared to responses induced by the whole $S$ DNA vaccine $\left(E_{50}\right.$ of 1389 and 644 respectively). The sera were also assessed in a similar antibody binding assay on the MesoScale Discovery platform that includes the whole spike and RBD proteins from original Lineage A, B.1.351 (Beta), B.1.1.7 (Alpha) and P.1 (Gamma) variants (Supplementary Figure 2) where the same pattern of responses was observed. Sera from immunised mice showed similar reactivity to either the original Lineage A and B.1.1.7 (Alpha) variants or the B.1.351 (Beta) and P.1 (Gamma) variants, as might be expected based on their RBD mutations. Interestingly, the sera from mice vaccinated with the original Lineage $A$ vaccine and the B.1.351 (Beta) variant vaccine showed similar titres of antibodies recognising the Lineage A N protein and a N protein variant containing the D3L, R203K, G204R and S235F mutations, two of which are also found in the B.1.1.7 (Alpha) variant (Supplementary Figure 3 ), suggesting perhaps that $\mathrm{N}$ protein specific antibodies may be more cross-reactive or bind to conserved regions of the $\mathrm{N}$ protein.

The ability of sera from immunised mice to inhibit the binding of the ACE2 receptor to the variant RBD or whole $S$ proteins was assessed using the MesoScale Discovery platform. Inhibition of RBD binding to ACE2 was higher for sera from mice vaccinated with the original Lineage A vaccine construct and the B.1.351 (Beta) variant vaccine construct compared to that seen with the NIBSC 20/136 control (Figure 6Ci). In contrast, sera from mice immunised with whole S DNA showed a lower capacity to inhibit ACE2 binding which was 
similar to that of the NIBSC 20/136 control. Sera from mice immunised with the original Lineage A vaccine construct inhibited $80-100 \%$ of ACE2 binding to the original Lineage A RBD and B.1.1.7 (Alpha) variants with a drop to 50-60\% against the B.1.351 (Beta) and P.1 (Gamma) RBD variants. The reverse is seen in sera from mice immunised with the B.1.351 (Beta) variant vaccine. Despite a reduction in the inhibition of ACE2 binding to the B.1.351 (Beta) and P.1 (Gamma) RBD variants, the inhibition levels remain above those seen using sera from whole S DNA immunised mice. A similar trend is seen in the ACE2 receptor binding inhibition assay with the variant whole $\mathrm{S}$ proteins (Figure 6Cii).

Sera from mice immunised with the original Lineage A or B.1.351 (Beta) variant vaccines were also assessed in pseudotype and live virus neutralisation tests against the original Lineage A and B.1.351 (Beta) variants. Sera from mice immunised with the original variant vaccine showed potent neutralisation of the original Lineage A pseudotype, with reduced efficacy against the B.1.351 (Beta) variant vaccine $\left(I_{50}\right.$ values of 6232 and 2137 respectively) (Figure 6D). Sera from mice immunised with either vaccine showed neutralisation of the B.1.351 (Beta) pseudotype variant, but little difference was noted $\left(\mathrm{ID}_{50}\right.$ values of 948 and 997 , respectively). In the live virus neutralisation assay sera from mice immunised with either the original Lineage A or the B.1.351 (Beta) variant vaccines neutralised of the original Lineage $A$ virus with $I D_{50}$ values of 4964 and 1334 respectively and both are better than NIBSC controls (Figure 6E).

In contrast to the antibody responses, the $\mathrm{T}$ cell responses did not seem to be impacted by variations between the virus strains (Figure 6F). Splenocytes from mice immunised with either the original Lineage A vaccine or the B.1.351 (Beta) vaccine were stimulated ex vivo with RBD and $\mathrm{N}$ peptide pools derived from the original sequence. T cell responses specific for RBD and $\mathrm{N}$ were detected with little difference between the response induced by the different vaccine constructs. These results suggest that mutations in the B.1.351 (Beta) variant have less impact on the $\mathrm{T}$ cell responses.

\section{Discussion}

We describe the development of a DNA vectored vaccine targeting both $\mathrm{S}$ and $\mathrm{N}$ proteins of SARS-CoV-2. In this study, we have demonstrated that the vaccine induces CD4 and CD8 $T$ cell responses to both $\mathrm{N}$ and RBD proteins in addition to eliciting potent neutralising antibody responses. We have shown the stimulation of $N$ and RBD peptide specific $T$ cell responses in several mouse strains, demonstrating that peptides derived from $N$ and RBD can be presented via various HLA alleles, thereby indicating the broad application of this vaccine in populations possessing a diverse range of HLA alleles. In responding immunised 
mice T cells released IFNy and TNFa upon stimulation in vitro, two Th1 cytokines required to induce potent immune responses, with the absence of IL-10 and IL-4 that could potentially induce damaging Th2 responses. Strong $T$ cell immune responses were induced by vaccines based on the original Lineage A SARS-CoV-2 isolate and the B.1.351 (Beta) variant, suggesting that the mutations may not be as significant for evading $T$ cell responses as they are for antibody responses. These data support the recent report from Tarke et al. suggesting SARS-CoV-2 variants have little impact on the T cell responses induced [40]. A strong $\mathrm{T}$ cell response is not only essential for the generation of humoral immunity in coronavirus infection [41] but has also been shown to persist over time and is therefore likely to be important for long term protection [22, 42]. Grifoni et al. have indeed shown the importance of both $\mathrm{T}$ cell and humoral immunity to $\mathrm{S}$ and $\mathrm{N}$ proteins for SARS-CoV-2 protection [16]. Evidence from SARS-CoV demonstrates the persistence of $\mathrm{T}$ cell responses to both $S$ and $N$ proteins up to 11 years post infection [42]. In addition, studies in mouse models of SARS-CoV have shown that memory CD8 T cells provide efficient protection from SARS-CoV infection [43]. Therefore, to be most effective, immunity stimulated by vaccination will likely need to comprise of both potent virus-specific CD8 and CD4 T cell responses as well as neutralising antibody responses. Several reports using murine models indicate that a strong Th1 response alongside virus specific CD8 response and virus specific neutralising antibodies are necessary for successful control of SARS-CoV and MERS [44, 45]. Although it is too early to determine the full extent of longevity of the T-cell responses for SARS-CoV-2 in humans, infection-specific memory $\mathrm{T}$ cells have been detected in convalescent patients and responses can be detected up to 18 weeks after infection. Interestingly the responses to $S$ antigen in convalescent patients appear superior to those detected in individuals vaccinated with the current approved vaccines [46] which is consistent with our unpublished data analysing responses to SARS-CoV-2 in humans. Studies by Ferretti et al. and Peng et al. reveal that SARS-CoV-2 reactive memory $\mathrm{T}$ cells in convalescent patients were more prevalent to antigens that are not subject to mutational variation such as the $\mathrm{N}$ protein $[47,48]$. In further support of these data, the study by Le Bert et al demonstrated that $\mathrm{N}$ protein specific $\mathrm{T}$ cell responses in patients who were infected with SARS-Co-V were more likely to cross react with homologous SARS-CoV-2 peptides than those from NSP7 and NSP13 [22]. This supports the rationale for targeting of both S and $\mathrm{N}$ proteins in vaccine design such as the strategy described in this study to induce both $\mathrm{T}$ cell and antibody mediated immunity.

Herein, we have achieved simultaneous production of strong neutralising antibody titres as well as potent CD8 and CD4 T cell responses to epitopes from both SARS-CoV-2 S and N proteins. The RBD monomer elicited the strongest neutralising antibody responses with $\mathrm{ID}_{50}$ 
titres of $>5000$. In this study, these titres were higher than those elicited by a DNA vaccine encoding whole $S$ protein, which was also reflected in the ACE2 binding inhibition assay, suggesting that vaccination with RBD may elicit higher neutralising antibody titres than vaccination with the complete $S$ antigen. These data compare favourably with other studies in which the whole $S$ protein or an RBD trimer have been used to produce vaccine candidates that generate potent neutralising antibodies [23, 49-52]. Indeed, it has been demonstrated that the majority of the neutralising antibodies to $S$ protein target the RBD, supporting the inclusion of just the RBD sequence in this bivalent vaccine [53].

In addition to strong RBD specific antibody responses the induction of antibody responses to the $\mathrm{N}$ protein were also detected. Although, these are likely to be non-neutralising antibodies, they often have the ability to clear viral infections [54-56]. Additionally, recent reports using lymphocytic choriomeningitis virus (LCMV) as a model virus suggest an alternative mechanism for the beneficial effect of $\mathrm{N}$ protein specific antibodies which involves the stimulation of antibody-dependent intracellular neutralisation and promotion of $\mathrm{N}$ specific cytotoxic T lymphocytes (CTLs) that efficiently clear virus infected cells [57]. The study by Caddy et al. suggests that $\mathrm{N}$-specific antibodies can bind $\mathrm{N}$ protein either released during viral lysis or expressed on the surface of infected cells and that the immune complex can be taken up by APCs, in which TRIM21 targets $\mathrm{N}$ protein for cytosolic degradation and the generation of cytotoxic $T$ cells against $N$ peptides. This is a rapid response and mediates viral clearance prior to the establishment of neutralising antibodies. In support of this hypothesis the vaccine construct containing $\mathrm{N}$ protein fused to the modified Fc sequence induced significantly better $\mathrm{T}$-cell responses to $\mathrm{N}$ protein and also elicited higher responses to RBD than a similar construct expressing the same RBD construct but with unmodified Fc linked to $\mathrm{N}$ (data not shown). This suggests that the modified N-Fc fusion is acting as an adjuvant and activating APCs to also enhance the T-cell response to other antigens. It is therefore possible that SARS-CoV-2 N specific antibodies could play a role in viral clearance and protection. A recent report by Matchett et al. has demonstrated the protective ability of an adenovirus type-5 (Ad5)-vectored vaccine encoding $N$ protein from SARS-CoV-2 in murine and hamster infection models and shows that protection is associated with the rapid stimulation of $\mathrm{N}$ protein specific $\mathrm{T}$ cell responses [58], thereby providing further evidence for the important role of $\mathrm{N}$ protein specific $\mathrm{T}$ cell responses. However, any evidence of $\mathrm{N}$ protein specific antibody response was not described. Reports by Rice et al and Seiling et al have also demonstrated the benefit of combining both $\mathrm{S}$ and $\mathrm{N}$ proteins as vaccine targets using a Ad5 vectored delivery platform [23, 59]. This delivers a modified $S$ protein to promote surface expression and a modified $\mathrm{N}$ protein to enhance $\mathrm{MHCl}$ and II presentation, resulting in the generation of both $\mathrm{N}$ and $\mathrm{S}$ specific $\mathrm{T}$ cell and neutralising antibody 
responses in preclinical studies [23]. In humans, T cell responses generated from a single dose of vaccine are of similar frequency to those seen in previously infected patients, although no data on antibody responses are reported [59].

The emergence of new SARS-CoV-2 variants has highlighted the importance of generating a vaccine mediated response that is effective against the variants as well as the original strain. Mutations in the $S$ protein have been shown to reduce the recognition by antibodies, thereby allowing the virus to escape antibody neutralising effects and increase the transmissibility, infection rate and disease severity [19, 20, 60,61]. Current vaccines approved for emergency use only encode the original Lineage A S protein sequence and have shown varying levels of cross-reactivity against the variant $S$ proteins with most reporting a drop in recognition and neutralisation efficacy, particularly against the B.1.351 (Beta) variant $[53,62$, 63]. In other reports, higher cross-reactivity is retained against the B.1.1.7 (Alpha) variant that has fewer significant mutations within the RBD sequence [61, 64]. B.1.1.7 (Alpha) variant contains only an asparagine $(\mathrm{N})$ to tyrosine $(\mathrm{Y})$ at position 501 within the RBD sequence whereas B.1.351 (Beta) variant contains this same N501Y mutation as well as two further mutations; lysine $(\mathrm{K})$ at position 417 to asparagine $(\mathrm{N})$, glutamic acid $(\mathrm{E})$ at position 484 to lysine $(\mathrm{K})$. The P.1 (Gamma) variant contains similar mutations within the RBD sequence (summarised in Supplementary Table 3). In our studies we have demonstrated a decrease in antibody titres and ACE2 binding inhibition against the B.1.351 (Beta) variant and P.1 (Gamma) variant $S$ proteins in sera from mice immunised with the DNA vaccine encoding the original Lineage A RBD sequence. However, these responses remain superior to those seen in the sera from mice immunised with whole $S$ encoding DNA. Encouragingly, these antibody responses showed a similar binding titre in ELISA and ACE2 binding inhibition with the B.1.1.7 (Alpha) variant $S$ protein suggesting that mutations in the B.1.1.7 (Alpha)variant $S$ protein do not reduce the antibody response induced by the DNA vaccine encoding the original Lineage A RBD sequence.

We have also demonstrated the efficacy of a vaccine construct encoding the B.1.351 (Beta) variant RBD sequence and show high titre antibody responses to the B.1.351 (Beta) variant $S$ protein that also cross react with the original Lineage A S protein. Recent reports in the literature suggest that sera from patients with the B.1.351 (Beta) variant of SARS-CoV-2 have high titre cross neutralising antibodies that also recognise the original SARS-CoV-2 virus [65]. In this report we demonstrate that although sera from mice immunised with the vaccine encoding the B.1.351 (Beta) variant RBD show a reduction in ACE2 binding inhibition of the Lineage A and B.1.1.7 (Alpha) variants, responses remain similar to those in 
sera from whole S DNA immunised mice and remain above $50 \%$ inhibition against all variants tested.

Interestingly, in pseudotype and live virus neutralisation assays there is less difference between the sera from the original Lineage A and B.1.351 (Beta) vaccinated mice with strong neutralisation of the Lineage $A$ variant from mice immunised with either vaccine showing $I D_{50}$ titres of $>1000$. It is possible that this reflects a polyclonal antibody response against both $\mathrm{S}$ and $\mathrm{N}$ proteins. Although a decrease in neutralisation of the B.1.351 (Beta) variant is seen for both vaccines, neutralisation titres are consistent with the current vaccines targeting $S$ protein only $[53,66]$. Despite this, these data imply that there is evidence of cross-reactivity and use of a vaccine encoding the B.1.351 (Beta) variant sequences may provide additional protection against multiple SARS-CoV-2 variants.

In summary, DNA provides a cost effective and rapid to manufacture product that can be easily adapted to encode sequences or mutations present in new variants. DNA vectors also lend themselves well to use in multiple homologous prime boost immunisation regimes, which is often not compatible with other viral vector-based vaccination strategies due to limitations of anti-vector immunity but may be vital to combat rapidly emerging virus variants. Data from our cancer vaccine platform demonstrates the stability of the DNA vector used in this study and its safety in human subjects [27]. The bivalent DNA SARS-CoV-2 vaccine stimulates strong humoral and cellular immunity that can be easily adapted to emerging virus variants. Furthermore, the responses elicited by both original Lineage A and B.1.351 (Beta) variant vaccines show cross-reactivity with multiple viral variants and support the potential clinical application of these vaccines.

\section{References}

1. Bosch, B.J., et al., The coronavirus spike protein is a class I virus fusion protein: structural and functional characterization of the fusion core complex. J Virol, 2003. 77(16): p. 8801-11.

2. Li, F., Structure, Function, and Evolution of Coronavirus Spike Proteins. Annu Rev Virol, 2016. 3(1): p. 237-261.

3. Walls, A.C., et al., Structure, Function, and Antigenicity of the SARS-CoV-2 Spike Glycoprotein. Cell, 2020. 181(2): p. 281-292.e6.

4. Zhou, P., et al., A pneumonia outbreak associated with a new coronavirus of probable bat origin. Nature, 2020. 579(7798): p. 270-273.

5. Beniac, D.R., et al., Architecture of the SARS coronavirus prefusion spike. Nat Struct Mol Biol, 2006. 13(8): p. 751-2. 
6. Delmas, B. and H. Laude, Assembly of coronavirus spike protein into trimers and its role in epitope expression. J Virol, 1990. 64(11): p. 5367-75.

7. Nal, B., et al., Differential maturation and subcellular localization of severe acute respiratory syndrome coronavirus surface proteins S, M and E. J Gen Virol, 2005. 86(Pt 5): p. 1423-1434.

8. Neuman, B.W., et al., A structural analysis of M protein in coronavirus assembly and morphology. J Struct Biol, 2011. 174(1): p. 11-22.

9. DeDiego, M.L., et al., A severe acute respiratory syndrome coronavirus that lacks the E gene is attenuated in vitro and in vivo. J Virol, 2007. 81(4): p. 1701-13.

10. Nieto-Torres, J.L., et al., Severe acute respiratory syndrome coronavirus envelope protein ion channel activity promotes virus fitness and pathogenesis. PLoS Pathog, 2014. 10(5): p. e1004077.

11. Chang, C.K., et al., Modular organization of SARS coronavirus nucleocapsid protein. J Biomed Sci, 2006. 13(1): p. 59-72.

12. Fehr, A.R. and S. Perlman, Coronaviruses: an overview of their replication and pathogenesis. Methods Mol Biol, 2015. 1282: p. 1-23.

13. Hurst, K.R., C.A. Koetzner, and P.S. Masters, Identification of in vivo-interacting domains of the murine coronavirus nucleocapsid protein. J Virol, 2009. 83(14): p. 7221-34.

14. Huang, C., et al., Clinical features of patients infected with 2019 novel coronavirus in Wuhan, China. Lancet, 2020. 395(10223): p. 497-506.

15. Suthar, M.S., et al., Rapid Generation of Neutralizing Antibody Responses in COVID19 Patients. Cell Rep Med, 2020. 1(3): p. 100040.

16. Grifoni, A., et al., Targets of T Cell Responses to SARS-CoV-2 Coronavirus in Humans with COVID-19 Disease and Unexposed Individuals. Cell, 2020. 181(7): p. 1489-1501 e15.

17. Hou, Y.J., et al., SARS-CoV-2 D614G variant exhibits efficient replication ex vivo and transmission in vivo. Science, 2020. 370(6523): p. 1464-1468.

18. Walker, A.S., et al., Increased infections, but not viral burden, with a new SARS-CoV2 variant. medRxiv, 2021: p. 2021.01.13.21249721.

19. Tegally, $\mathrm{H}$., et al., Emergence of a SARS-CoV-2 variant of concern with mutations in spike glycoprotein. Nature, 2021.

20. Thomson, E.C., et al., Circulating SARS-CoV-2 spike N439K variants maintain fitness while evading antibody-mediated immunity. Cell, 2021. 184(5): p. 11711187.e20. 
21. Dutta, N.K., K. Mazumdar, and J.T. Gordy, The Nucleocapsid Protein of SARS-CoV2: a Target for Vaccine Development. Journal of virology, 2020. 94(13): p. e0064720.

22. Le Bert, N., et al., SARS-CoV-2-specific T cell immunity in cases of COVID-19 and SARS, and uninfected controls. Nature, 2020. 584(7821): p. 457-462.

23. Rice, A., et al., A Next Generation Bivalent Human Ad5 COVID-19 Vaccine Delivering Both Spike and Nucleocapsid Antigens Elicits Th1 Dominant CD4+, CD8+ T-cell and Neutralizing Antibody Responses. bioRxiv, 2020: p. 2020.07.29.227595.

24. Metheringham, R.L., et al., Antibodies designed as effective cancer vaccines. MAbs, 2009. 1(1): p. 71-85.

25. Pudney, V.A., et al., DNA vaccination with $T$-cell epitopes encoded within $A b$ molecules induces high-avidity anti-tumor CD8+ T cells. Eur J Immunol, 2010. 40(3): p. 899-910.

26. Brentville, V.A., et al., High avidity cytotoxic $T$ lymphocytes can be selected into the memory pool but they are exquisitely sensitive to functional impairment. PLoS One, 2012. 7(7): p. e41112.

27. Patel, P.M., et al., Targeting gp100 and TRP-2 with a DNA vaccine: Incorporating T cell epitopes with a human IgG1 antibody induces potent $T$ cell responses that are associated with favourable clinical outcome in a phase I/II trial. Oncoimmunology, 2018. 7(6): p. e1433516.

28. Vankemmelbeke, M., et al., Engineering the Human FC Region Enables Direct Cell Killing by Cancer Glycan-Targeting Antibodies without the Need for Immune Effector Cells or Complement. Cancer Res, 2020. 80(16): p. 3399-3412.

29. Zaki, A.M., et al., Isolation of a novel coronavirus from a man with pneumonia in Saudi Arabia. N Engl J Med, 2012. 367(19): p. 1814-20.

30. Sanger, F., S. Nicklen, and A.R. Coulson, DNA sequencing with chain-terminating inhibitors. Proc Natl Acad Sci U S A, 1977. 74(12): p. 5463-7.

31. Zhang, Q., et al., Immune epitope database analysis resource (IEDB-AR). Nucleic Acids Res, 2008. 36(Web Server issue): p. W513-8.

32. Capone, S., et al., Immunogenicity of a new gorilla adenovirus vaccine candidate for COVID-19. Mol Ther, 2021.

33. Tighe, P.J., et al., Potent anti-SARS-CoV-2 Antibody Responses are Associated with Better Prognosis in Hospital Inpatient COVID-19 Disease. medRxiv, 2020: p. 2020.08.22.20176834.

34. Coleman, C.M., et al., Purified coronavirus spike protein nanoparticles induce coronavirus neutralizing antibodies in mice. Vaccine, 2014. 32(26): p. 3169-3174. 
35. Ahmed, S.F., A.A. Quadeer, and M.R. McKay, Preliminary Identification of Potential Vaccine Targets for the COVID-19 Coronavirus (SARS-CoV-2) Based on SARS-CoV Immunological Studies. Viruses, 2020. 12(3).

36. Bhattacharya, M., et al., Development of epitope-based peptide vaccine against novel coronavirus 2019 (SARS-COV-2): Immunoinformatics approach. J Med Virol, 2020. 92(6): p. 618-631.

37. Muik, A., et al., Neutralization of SARS-CoV-2 lineage B.1.1.7 pseudovirus by BNT162b2 vaccine-elicited human sera. Science, 2021. 371: p. 1152-1153.

38. Tada, T., et al., Neutralization of viruses with European, South African, and United States SARS-CoV-2 variant spike proteins by convalescent sera and BNT162b2 mRNA vaccine-elicited antibodies. bioRxiv, 2021: p. 10.1101/2021.02.05.430003.

39. Chen, R.E., et al., Resistance of SARS-CoV-2 variants to neutralization by monoclonal and serum-derived polyclonal antibodies. Nat Med, 2021. 27(4): p. 717726.

40. Tarke, A., et al., Negligible impact of SARS-CoV-2 variants on CD4 (+) and CD8 (+) $T$ cell reactivity in COVID-19 exposed donors and vaccinees. bioRxiv : the preprint server for biology, 2021: p. 2021.02.27.433180.

41. Altmann, D.M. and R.J. Boyton, SARS-CoV-2 T cell immunity: Specificity, function, durability, and role in protection. Sci Immunol, 2020. 5(49).

42. Ng, O.W., et al., Memory T cell responses targeting the SARS coronavirus persist up to 11 years post-infection. Vaccine, 2016. 34(17): p. 2008-14.

43. Yang, Z.Y., et al., A DNA vaccine induces SARS coronavirus neutralization and protective immunity in mice. Nature, 2004. 428(6982): p. 561-4.

44. Channappanavar, R., et al., Virus-specific memory CD8 T cells provide substantial protection from lethal severe acute respiratory syndrome coronavirus infection. $\mathrm{J}$ Virol, 2014. 88(19): p. 11034-44.

45. Zhao, J., et al., Airway Memory CD4(+) T Cells Mediate Protective Immunity against Emerging Respiratory Coronaviruses. Immunity, 2016. 44(6): p. 1379-91.

46. Reynolds, C.J., et al., Prior SARS-CoV-2 infection rescues $B$ and $T$ cell responses to variants after first vaccine dose. Science, 2021.

47. Ferretti, A.P., et al., Unbiased Screens Show CD8(+) T Cells of COVID-19 Patients Recognize Shared Epitopes in SARS-CoV-2 that Largely Reside outside the Spike Protein. Immunity, 2020. 53(5): p. 1095-1107.e3.

48. Peng, Y., et al., Broad and strong memory CD4(+) and CD8(+) T cells induced by SARS-CoV-2 in UK convalescent individuals following COVID-19. Nat Immunol, 2020. 21(11): p. 1336-1345. 
49. Erasmus, J.H., et al., An Alphavirus-derived replicon RNA vaccine induces SARSCoV-2 neutralizing antibody and $T$ cell responses in mice and nonhuman primates. Sci Transl Med, 2020. 12(555).

50. Graham, S.P., et al., Evaluation of the immunogenicity of prime-boost vaccination with the replication-deficient viral vectored COVID-19 vaccine candidate ChAdOx1 nCoV-19. NPJ Vaccines, 2020. 5: p. 69.

51. McKay, P.F., et al., Self-amplifying RNA SARS-CoV-2 lipid nanoparticle vaccine candidate induces high neutralizing antibody titers in mice. Nat Commun, 2020. 11(1): p. 3523.

52. Smith, T.R.F., et al., Immunogenicity of a DNA vaccine candidate for COVID-19. Nat Commun, 2020. 11(1): p. 2601.

53. Wang, Z., et al., mRNA vaccine-elicited antibodies to SARS-CoV-2 and circulating variants. Nature, 2021.

54. Bootz, A., et al., Protective capacity of neutralizing and non-neutralizing antibodies against glycoprotein B of cytomegalovirus. PLoS Pathog, 2017. 13(8): p. e1006601.

55. Carragher, D.M., et al., A novel role for non-neutralizing antibodies against nucleoprotein in facilitating resistance to influenza virus. J Immunol, 2008. 181(6): p. 4168-76.

56. Mayr, L.M., B. Su, and C. Moog, Non-Neutralizing Antibodies Directed against HIV and Their Functions. Front Immunol, 2017. 8: p. 1590.

57. Caddy, S.L., et al., Viral nucleoprotein antibodies activate TRIM21 and induce T cell immunity. Embo j, 2020: p. e106228.

58. Matchett, W.E., et al., Nucleocapsid vaccine elicits spike-independent SARS-CoV-2 protective immunity. bioRxiv, 2021: p. 2021.04.26.441518.

59. Sieling, P., et al., Th1 Dominant Nucleocapsid and Spike Antigen-Specific CD4+ and CD8+ Memory $T$ Cell Recall Induced by hAd5 S-Fusion + N-ETSD Infection of Autologous Dendritic Cells from Patients Previously Infected with SARS-CoV-2. medRxiv, 2020: p. 2020.11.04.20225417.

60. Wibmer, C.K., et al., SARS-CoV-2 501Y.V2 escapes neutralization by South African COVID-19 donor plasma. Nature Medicine, 2021.

61. Wang, P., et al., Increased Resistance of SARS-CoV-2 Variants B.1.351 and B.1.1.7 to Antibody Neutralization. bioRxiv, 2021.

62. Zhou, D., et al., Evidence of escape of SARS-CoV-2 variant B.1.351 from natural and vaccine-induced sera. Cell, 2021.

63. Supasa, P., et al., Reduced neutralization of SARS-CoV-2 B.1.1.7 variant by convalescent and vaccine sera. Cell, 2021. 
64. Muik, A., et al., Neutralization of SARS-CoV-2 lineage B.1.1.7 pseudovirus by BNT162b2 vaccine-elicited human sera. Science, 2021. 371(6534): p. 1152-1153.

65. Moyo-Gwete, T., et al., SARS-CoV-2 501Y.V2 (B.1.351) elicits cross-reactive neutralizing antibodies. bioRxiv, 2021.

66. Stamatatos, L., et al., mRNA vaccination boosts cross-variant neutralizing antibodies elicited by SARS-CoV-2 infection. Science, 2021.

\section{Figure legends}

Figure 1. Schematic representation of the DNA SARS-CoV-2 plasmids and expression of $\mathrm{N}$ and RBD proteins. A, DNA constructs expressing $N$ and RBD variants (i)-(ix). Spike RBD and NP variant chains are within expression cassettes 1 and 2 of the pVaxDC vector. Numbers indicate amino acids. SP: signal peptide/ Human lgH Leader, RBD: receptorbinding domain, Fd: Fibritin fold on trimer motif from T4 bacteriophage (GYIPEAPRDGQAYVRKDGEWVLLSTFL). DBM: Disulphide bridge motif. Both fibritin fold on and disulphide bridge motif are attached to the S RBD via glycine/serine linkers. In some constructs the Spike RBD domain and N protein is fused inframe with HuigG1 FC or the improved modified version of the constant domain, designated iV1.

RBD (i) and N (ii) protein expression from transfected Expi293 ${ }^{\mathrm{TM}}$ cells in the supernatant (B) and cell lysate $(\mathrm{C})$.

Figure 2. Linkage of $\mathrm{N}$ protein to modified Fc stimulates superior $\mathrm{N}$ and RBD specific $\mathrm{T}$ cell responses. A, BALB/c, C57BI/6 or HLA-A2 transgenic mice immunised with DNA constructs expressing $\mathrm{N}, \mathrm{N}$ linked to $\mathrm{Fc}$ or $\mathrm{N}$ linked to modified Fc (iV1) and T cell responses monitored by IFNy ELISpot assay to $\mathrm{N}$ peptide pool (i) or N 138-146 peptide (ii). B, Assessment of RBD specific $T$ cell responses in HLA-A2 transgenic mice using RBD peptide pool (i) or RBD 417-425 peptide (ii) from constructs containing RBD alongside $\mathrm{N}, \mathrm{N}$ linked to Fc or $\mathrm{N}$ linked to modified Fc (iV1). C, Assessment of RBD specific T cell responses using RBD peptide pool (i and iii) or RBD 417-425 peptide (ii) from constructs containing RBD variants alongside $\mathrm{N}$ linked to modified Fc (iV1) ( $\mathrm{i}$ and ii) or RBD monomer alongside $\mathrm{N}$ linked to modified Fc (iV1) compared to DNA encoding the whole $S$ protein (iii). Responses are measured as spots $/ 10^{6}$ splenocytes. Symbols represent mean response for individual mice, line represents mean value between mice. Significant $P$ values are shown from studies with matched data points, Data is collated from multiple independent studies. 
Figure 3. DNA vaccination induces strong CD8 and CD4 $T$ cell responses. $B A L B / c(A)$, C57BI/6 (B) or HLA-A2 transgenic (C) mice immunised with DNA constructs expressing RBD alongside $\mathrm{N}$ linked to modified $\mathrm{Fc}$ (iV1) and $\mathrm{T}$ cell responses monitored by IFNY ELISpot assay to RBD or $\mathrm{N}$ peptide pools and individual peptides. Symbols represent mean response for individual mice, line represents mean value between mice. Data is collated from multiple independent studies and $p$ values shown are compared to media control. $D$, Responses from HLA-A2 transgenic mice to RBD 417-425 or N 138-146 peptides assessed in the presence of CD4 or CD8 blocking antibodies. E, Responses from BALB/c mice to RBD 505-524 (i) or N 80-100 (ii) peptides assessed in the presence of CD4 or CD8 blocking antibodies. Results are representative of at least two independent experiments in which $n=3$ mice per group. Responses are measured as spots/million splenocytes.

Figure 4. Multi-cytokine $\mathrm{T}$ cell responses with Th1 polarisation. Intracellular cytokine staining for IFNy, TNFa, IL-10 and IL-4 in response to peptide restimulation or stimulation with anti-CD3 antibody positive control on splenocyte cultures expanded in vitro with S1 and $\mathrm{N}$ proteins (A and $\mathrm{C}$ ) or RBD 505-524 peptide (B) from BALB/C ( $\mathrm{A}$ and $\mathrm{B}$ ) or $\mathrm{C} 57 \mathrm{BI} / 6$ (C) mice immunised with DNA construct expressing RBD alongside $N$ linked to modified FC (iV1). Example staining plots (i) and percentage of CD4+ or CD8+ cells are shown (ii).

Figure 5. DNA vaccination induces anti-RBD neutralising and anti-N antibody responses. Sera from immunised mice analysed for anti-S1 (A) or anti-N (D) antibodies by ELISA. Data presented shows absorbance readings with sera titrations (i) and as total $\mu \mathrm{g} / \mathrm{mL}$ specific $\lg \mathrm{G}$ (ii) $\mathrm{EC}_{50}$ values were calculated and the quantity of $\mathrm{lg}$ in the sera was estimated from the $\mathrm{OD}$ value at a 1 in 3000 serum dilution using the standard curve of commercial murine S1 or $\mathrm{N}$ antibody.

Sera from BALB/c mice immunised with constructs containing the RBD monomer, trimer or monomer linked to $\mathrm{Fc}(\mathrm{B}), \mathrm{C} 57 \mathrm{BI} / 6$ mice immunised with construct containing the RBD monomer or whole S protein (C) and the NIBSC 20/136 standard were assessed for neutralisation at increasing sera dilutions (i) and $\mathrm{ID}_{50}$ values (ii).

Figure 6. DNA vaccination induces cross reactive antibody and $T$ cell responses. BALB/C mice were immunised with DNA constructs expressing original (A-F), B.1.351 (Beta) variant (B-F) RBD alongside $N$ linked to modified Fc (iV1) or whole S DNA (B and C). Sera from immunised mice were analysed for anti-S1 antibodies by ELISA using variant S1 proteins (A and $B$ ), in ACE2 binding inhibition assay versus RBD or whole $S$ protein (Meso Scale Discovery Platform) (C), in pseudotype neutralisation assay (D) or live virus neutralisation assay (E). Data are readings at different sera titrations and are representative of multiple 
bioRxiv preprint doi: https://doi.org/10.1101/2021.06.18.448932; this version posted June 18, 2021. The copyright holder for this preprint (which was not certified by peer review) is the author/funder, who has granted bioRxiv a license to display the preprint in perpetuity. It is made available under aCC-BY-NC 4.0 International license.

experiments. F, T cell responses in immunised mice monitored by IFNY ELISpot assay to RBD or $\mathrm{N}$ peptide pools. Symbols represent mean response for individual mice, line represents mean value between mice. Data are collated from multiple independent studies. 
(which was not certified by peer review) is the author/funder, who has granted bioRxiv a license to display the preprint in perpetuity. It is $m$ available under aCC-BY-NC 4.0 International license.

Figure 1

A

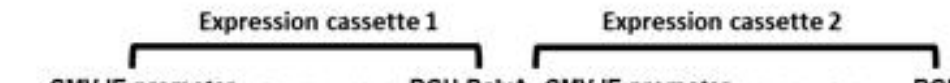

(i)

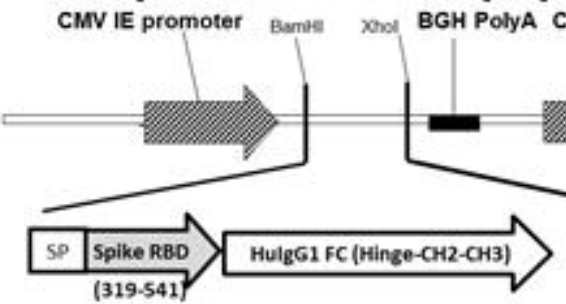

(ii)

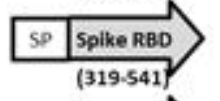

(iii)

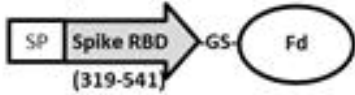

(iv)

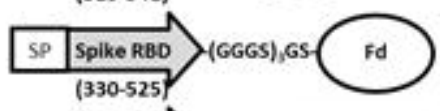

(v)

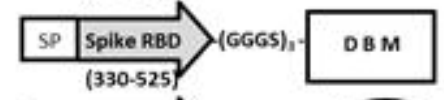

(vi)

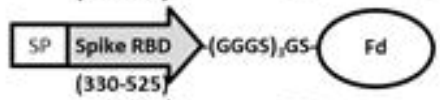

(vii)

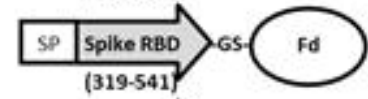

(viii)

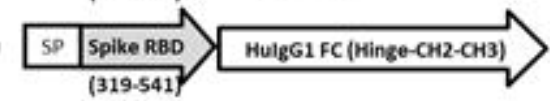

(ix)

$$
\begin{array}{|l|l|}
\hline \text { SPP } & \text { Spike RBD } \\
\hline
\end{array}
$$

B
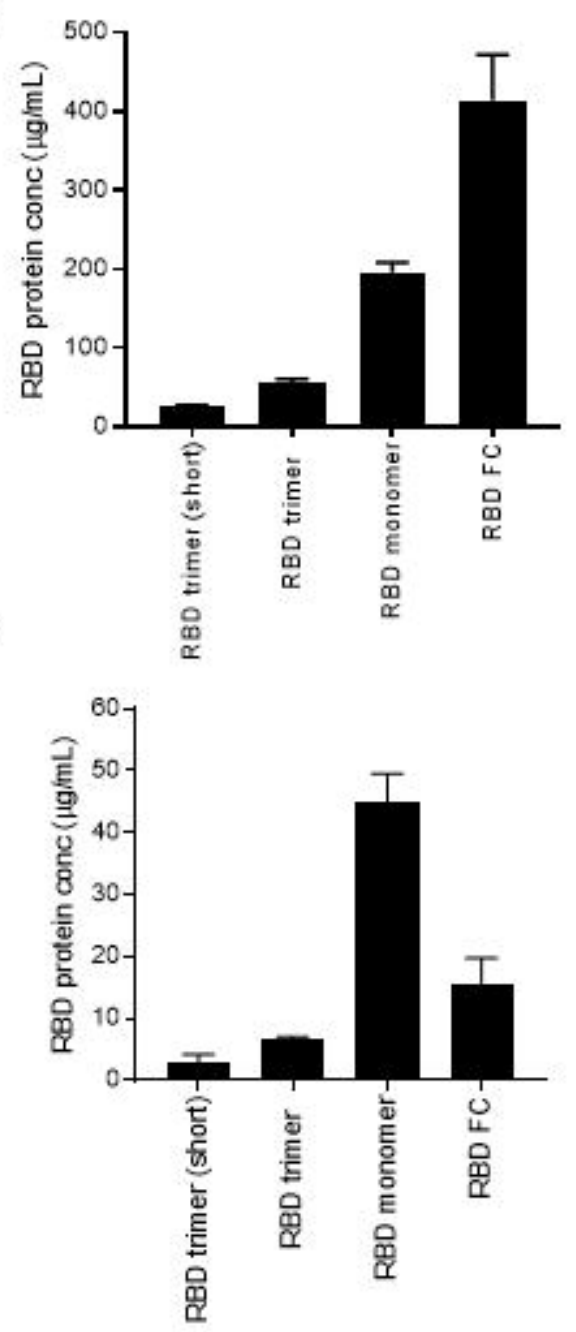

ii

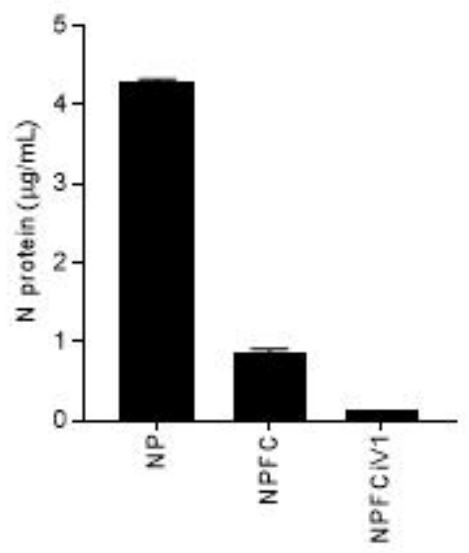

ii

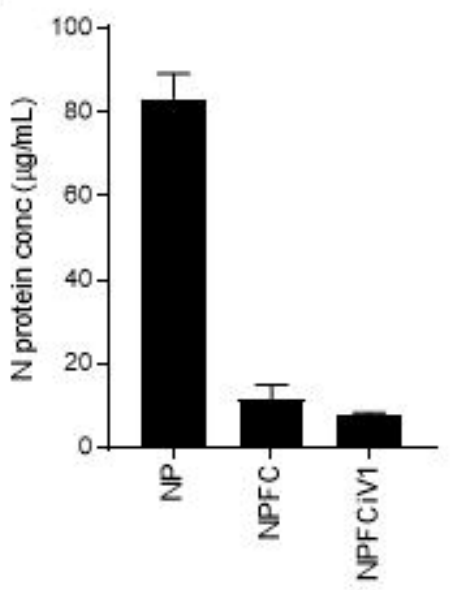



available under aCC-BY-NC 4.0 International license.

Figure 2

A

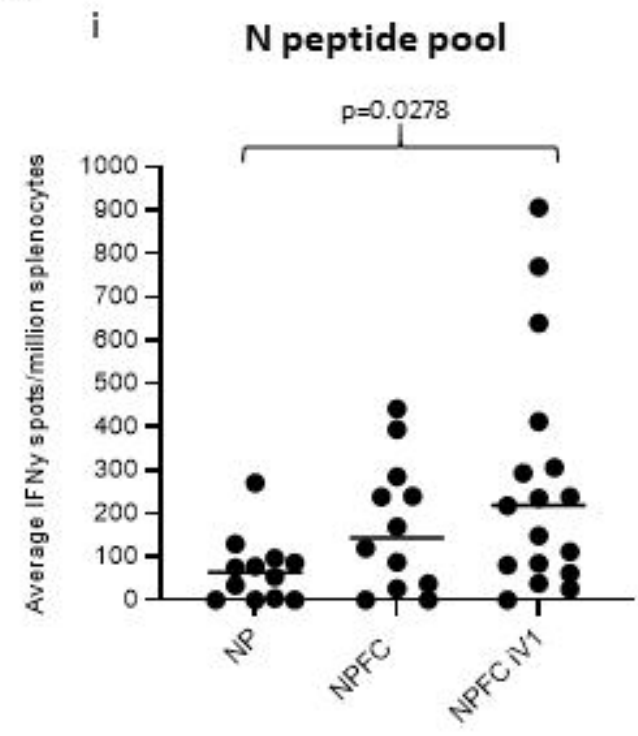

B

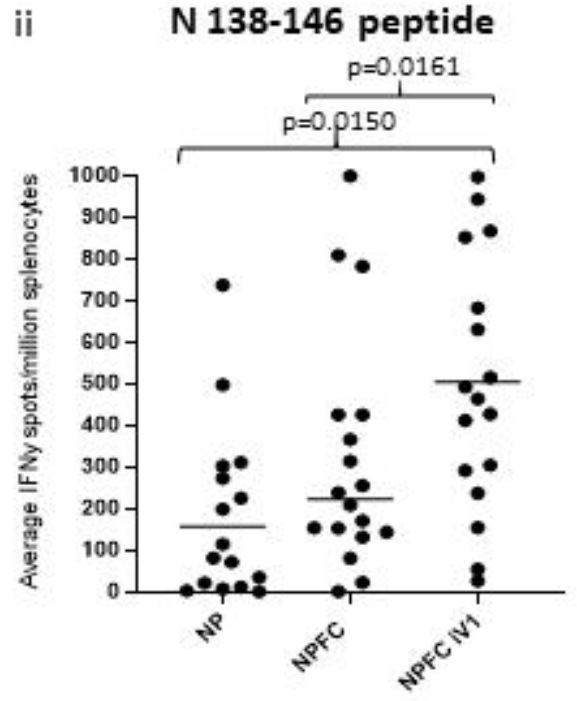

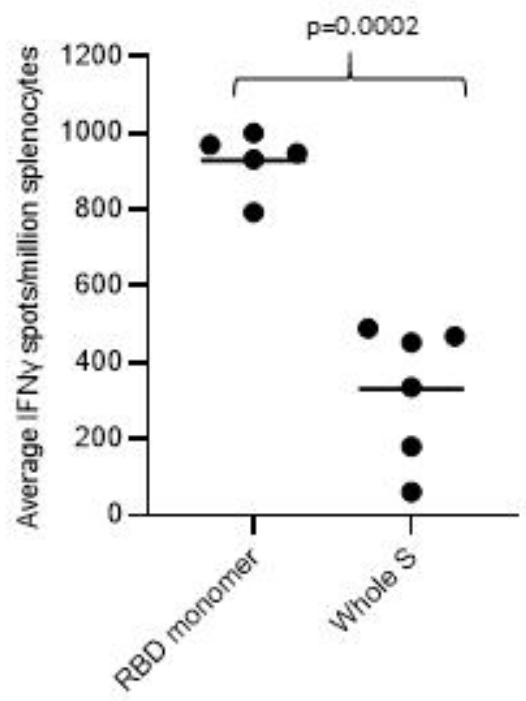


Figure 3

A

$\mathrm{BALB} / \mathrm{c}$ mice

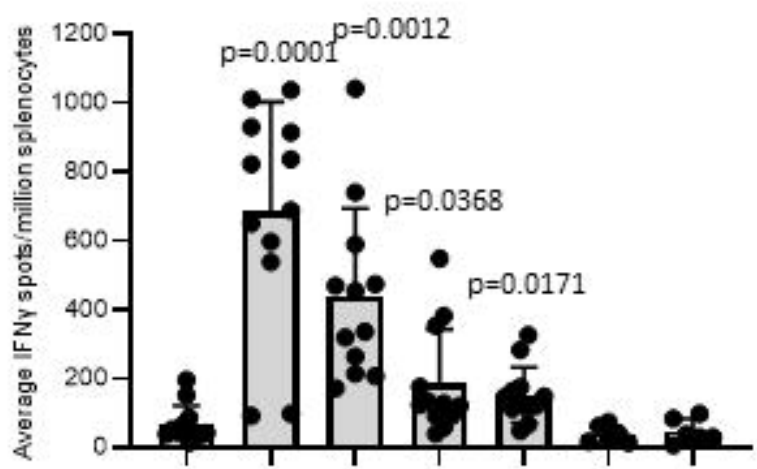

C

HLA-A2 Tg mice

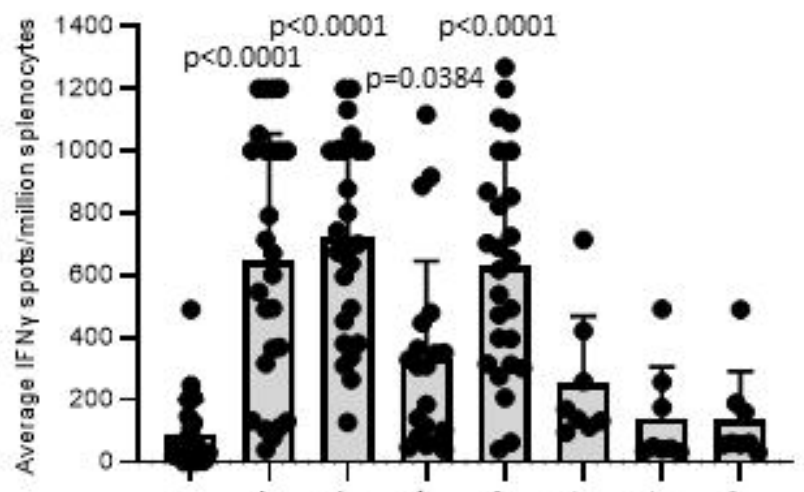

$\mathrm{E}$

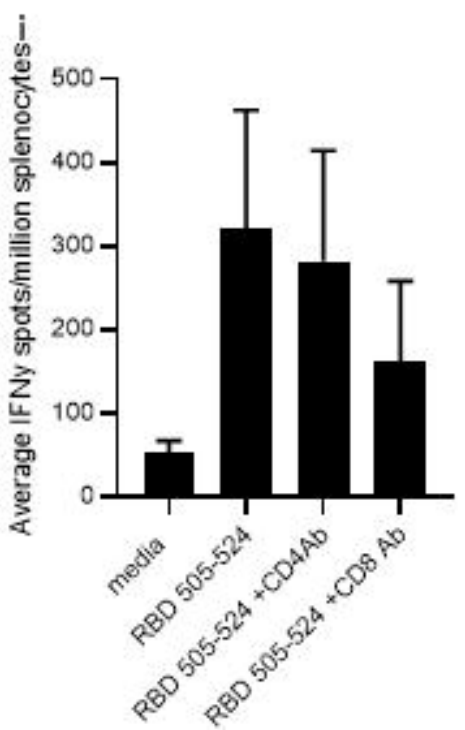

ii
B

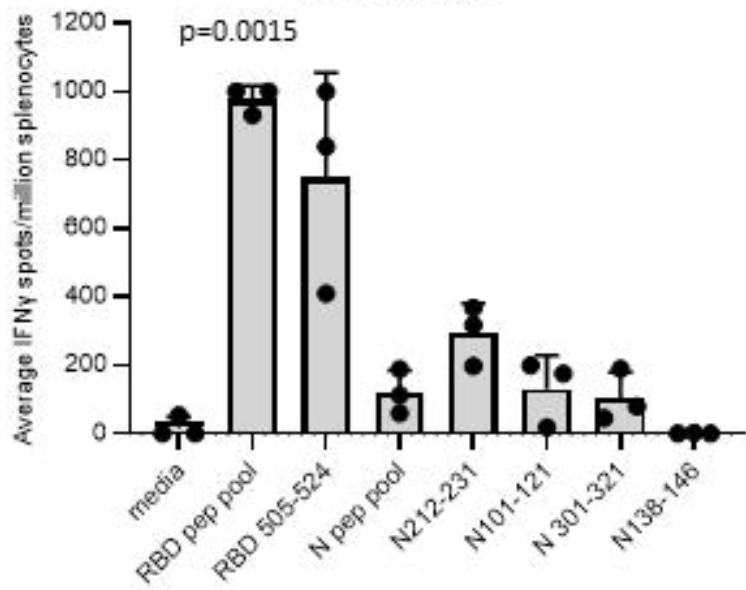

D

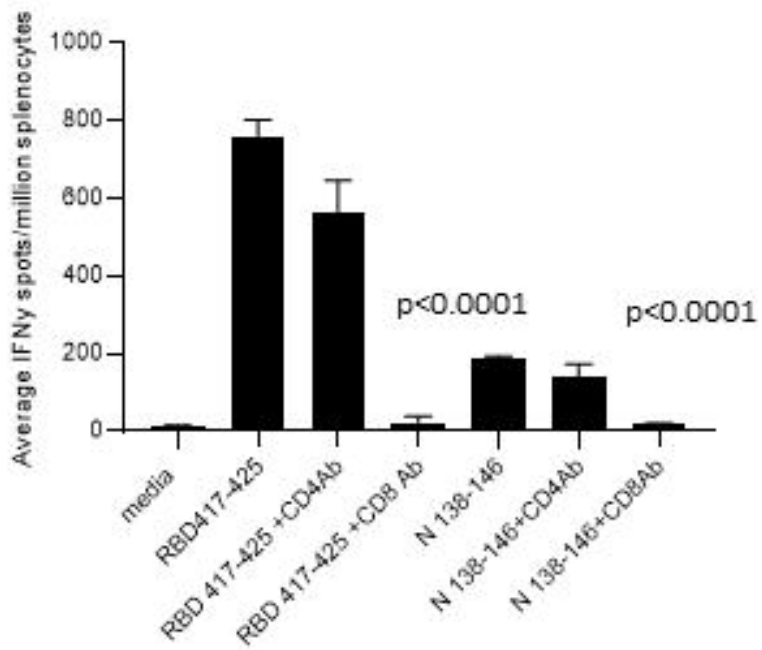

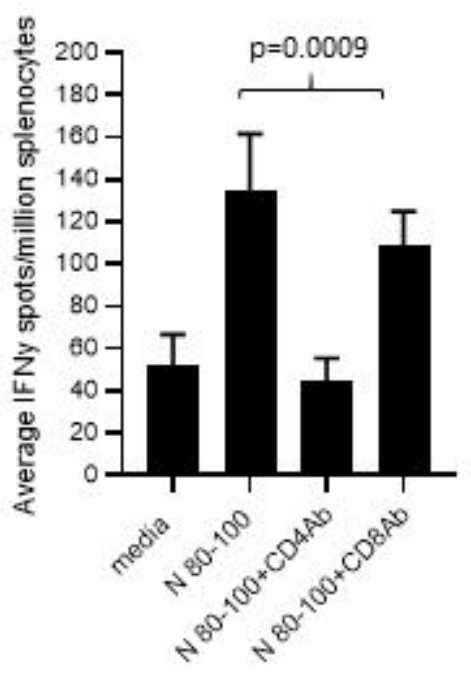


(which was not certified by peer review) is the author/funder, who has granted bioRxiv a license to display the preprint in perpetuity. It is $m$ available under aCC-BY-NC 4.0 International license.

Figure 4

A
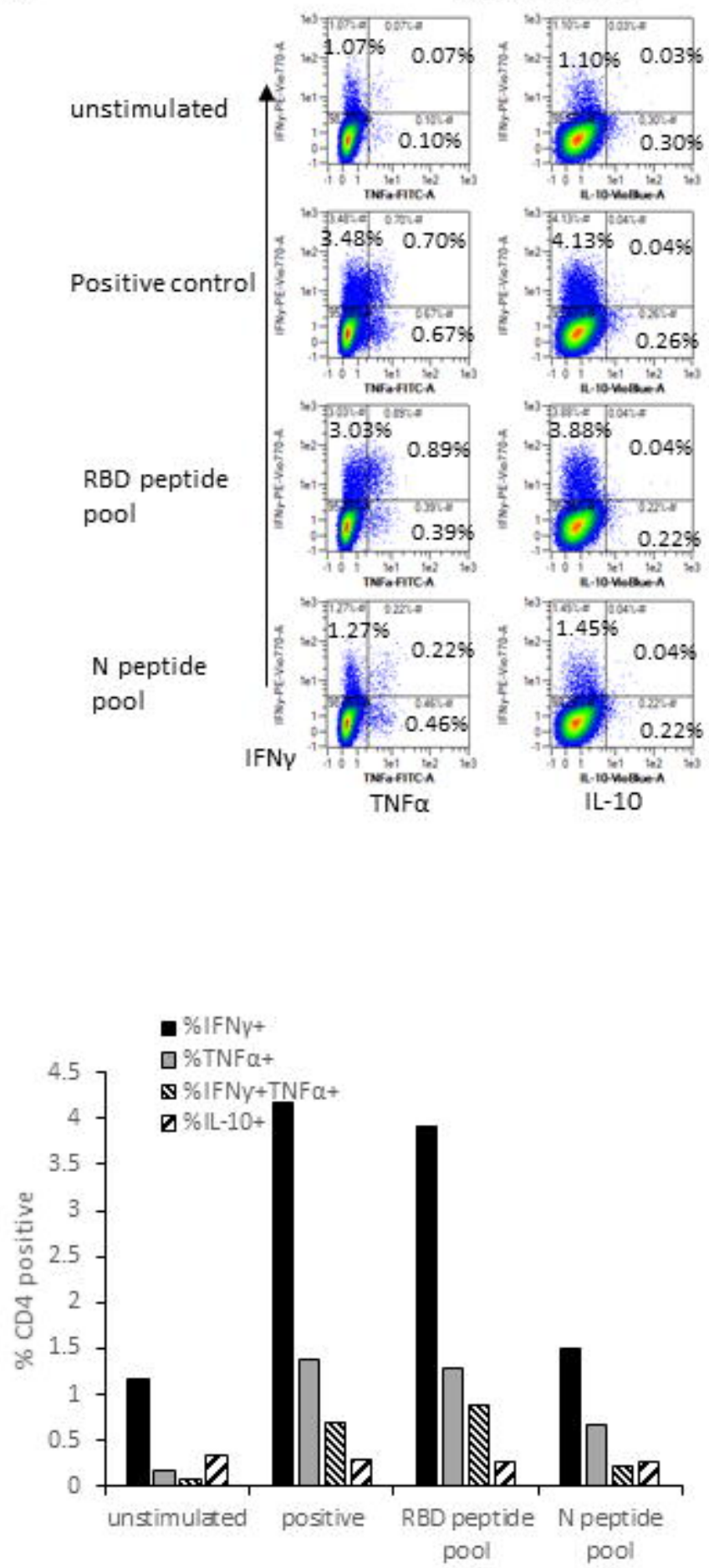

Gated on CD4-
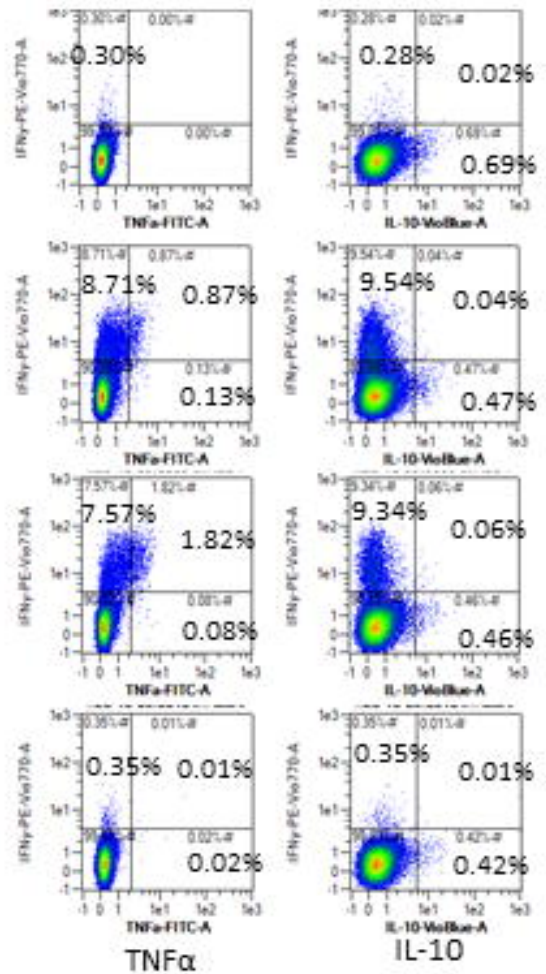

- $\%$ IFNy+ 口\%TNFa+

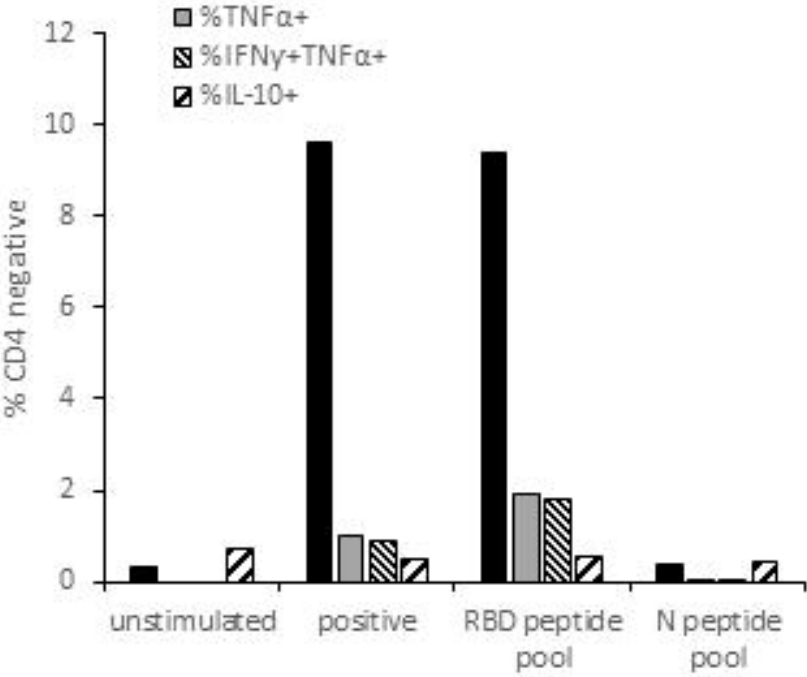


(which was not certified by peer review) is the author/funder, who has granted bioRxiv a license to display the preprint in perpetuity. It is $m$ available under aCC-BY-NC 4.0 International license.

\section{Figure 4}

B
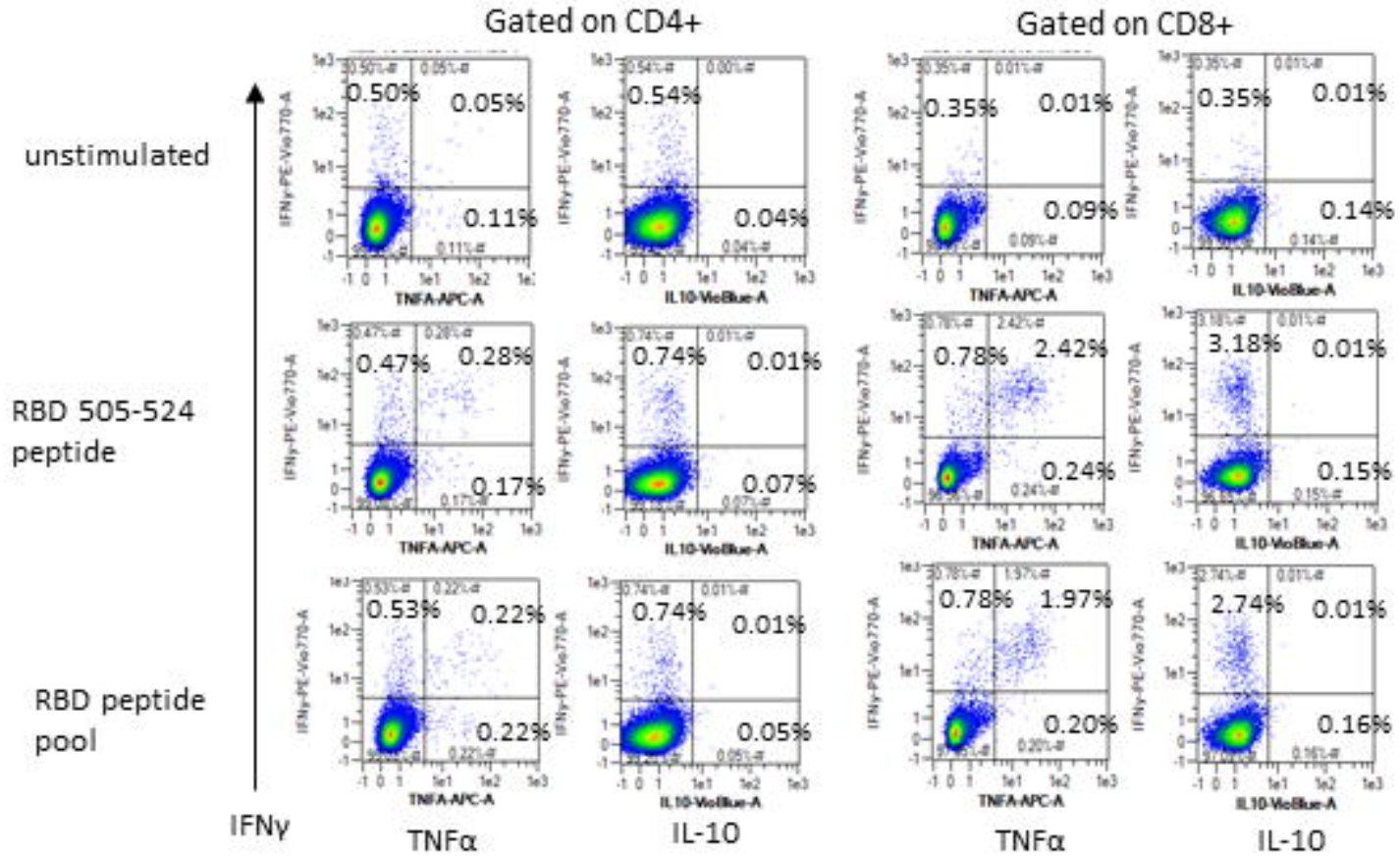

TNF $\alpha$

IL-10
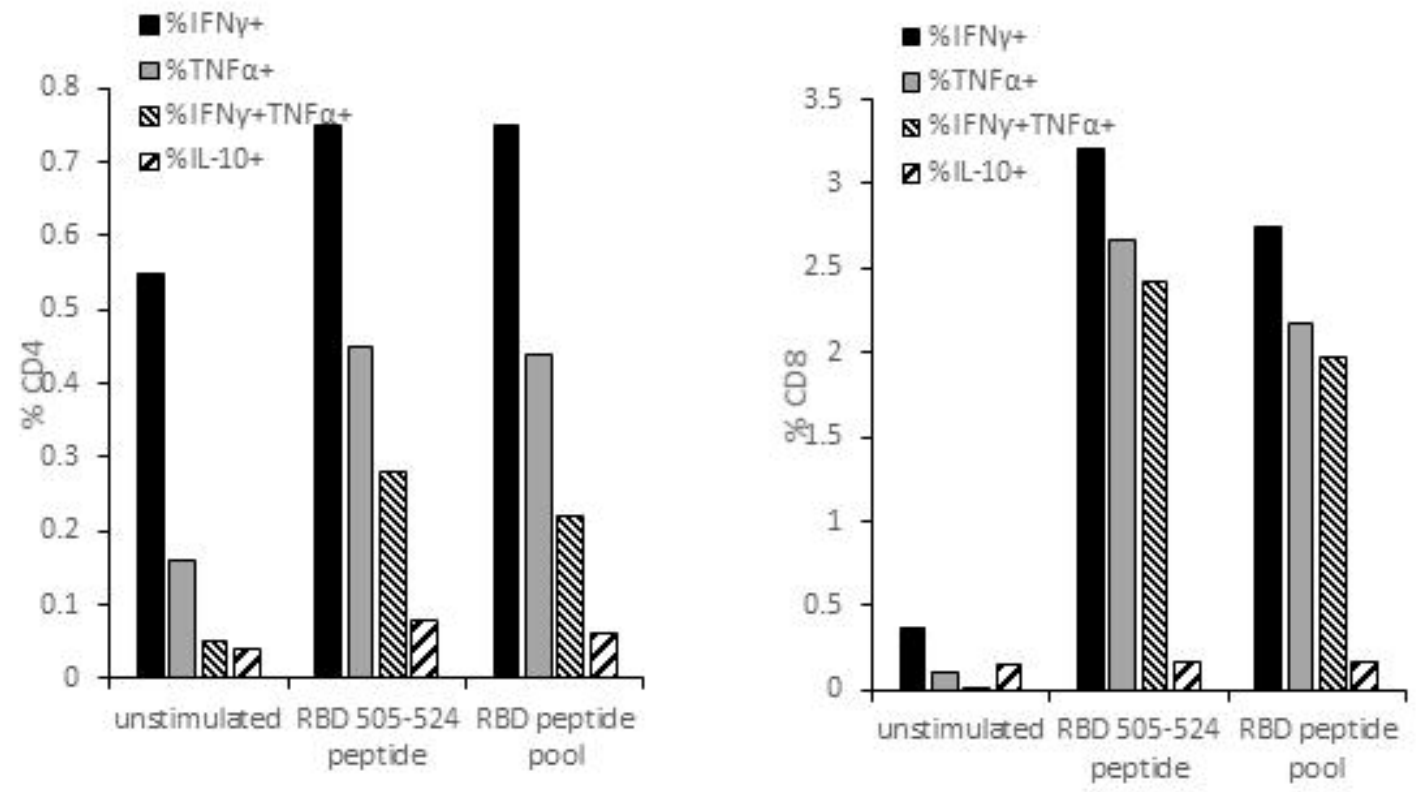
Figure 4

C

Gated on $\mathrm{CD} 4+$

unstimulated

pool

N $101-121$

peptide

RBD 505-524

peptide
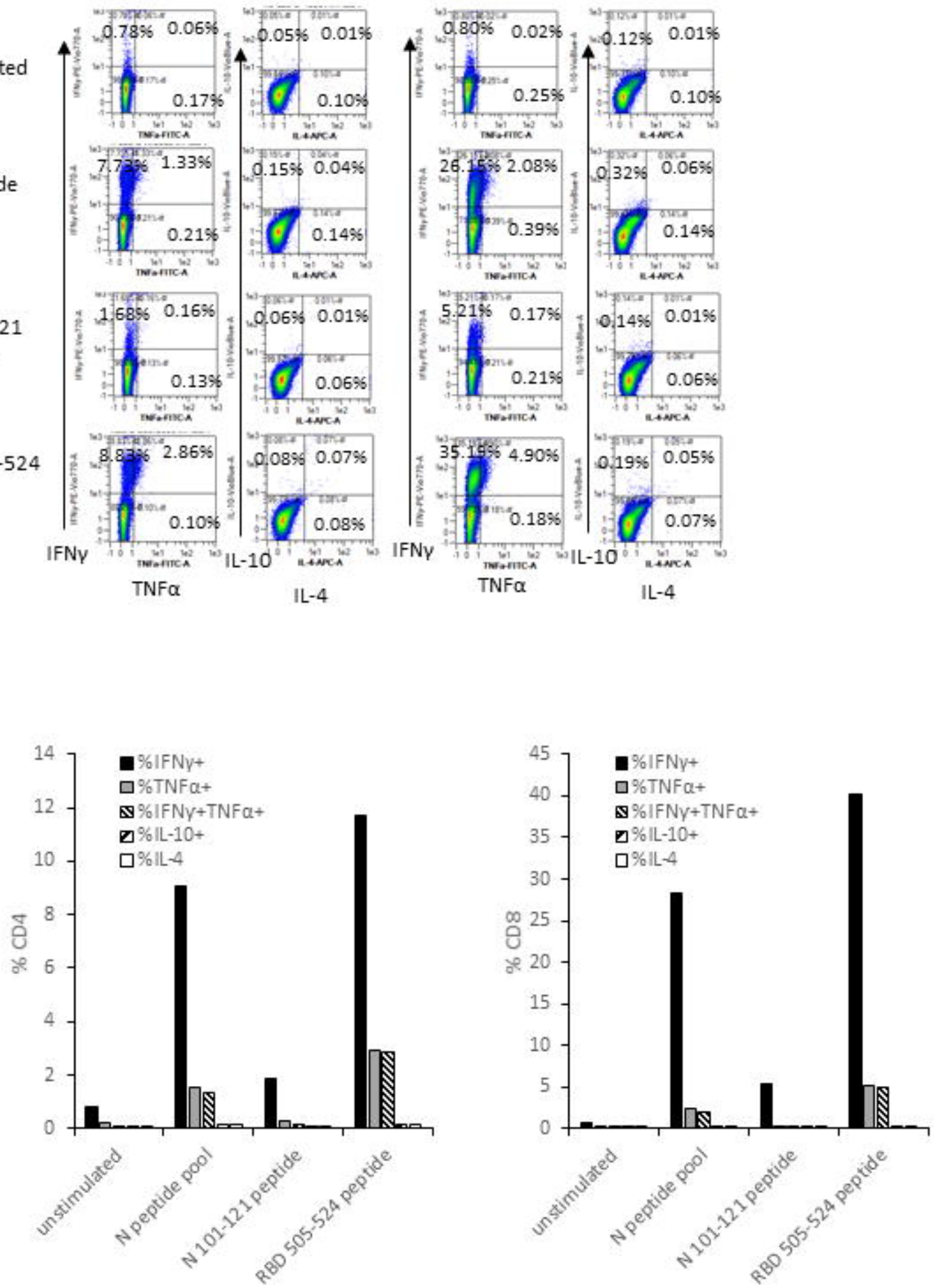
Figure 5

A i

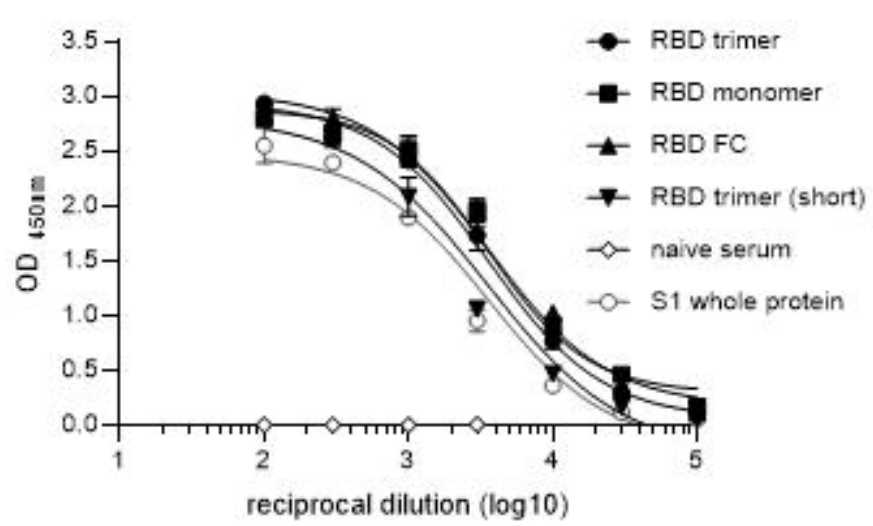

ii

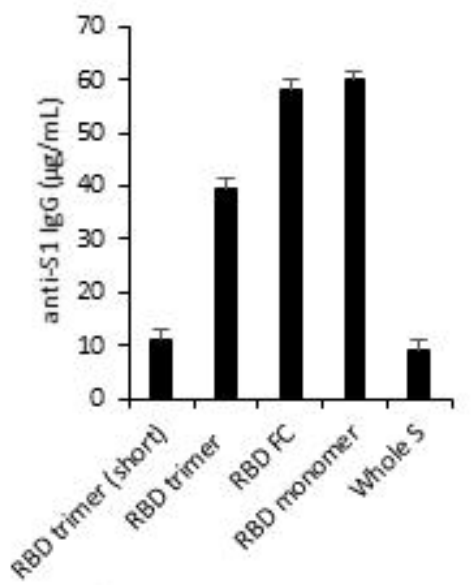

\begin{tabular}{|l|l|l|l|l|l|}
\hline & $\begin{array}{l}\text { RBD } \\
\text { trimer }\end{array}$ & $\begin{array}{l}\text { RBD } \\
\text { monomer }\end{array}$ & RBD FC & $\begin{array}{l}\text { RBD } \\
\text { trimer } \\
\text { (short) }\end{array}$ & $\begin{array}{l}\text { S1 } \\
\text { whole } \\
\text { protein }\end{array}$ \\
\hline $\mathrm{EC}_{\text {so }}$ & 4161 & 5355 & 5816 & 1937 & 1989 \\
\hline R squared & 0.9945 & 0.9943 & 0.9953 & 0.9949 & 0.9952 \\
\hline
\end{tabular}

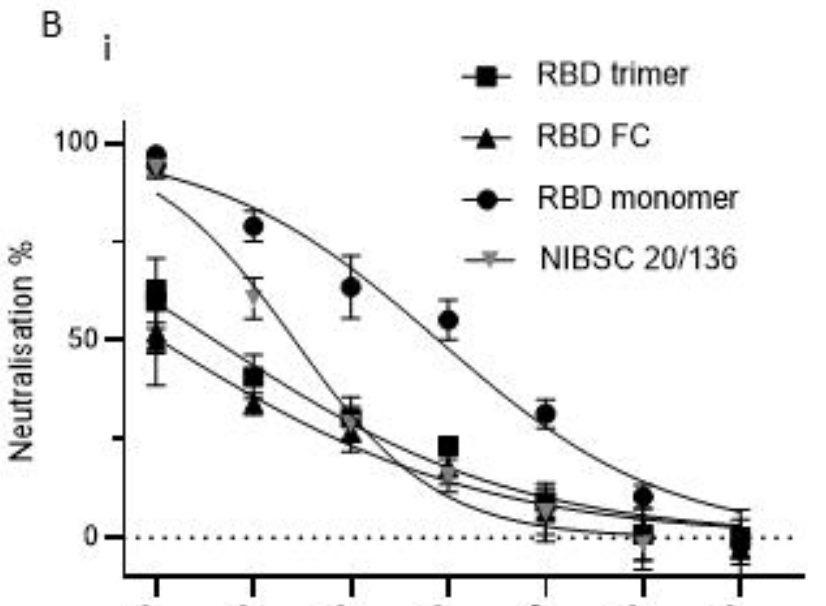

C

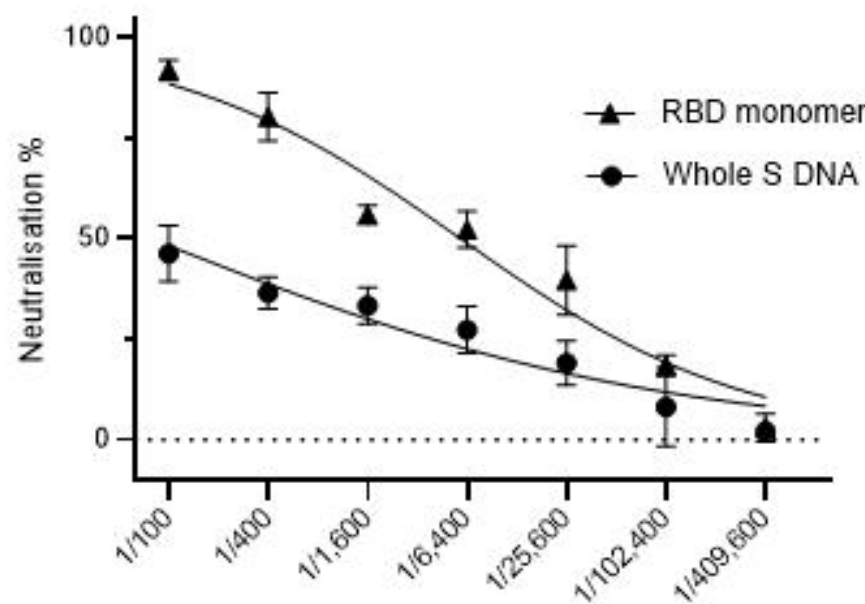

ii

\begin{tabular}{|l|l|l|l|l|}
\hline construct & $\begin{array}{l}\text { RBD } \\
\text { trimer }\end{array}$ & RBD FC & $\begin{array}{l}\text { RBD } \\
\text { monomer }\end{array}$ & $\begin{array}{l}\text { NIBSC } \\
20 / 136\end{array}$ \\
\hline$I_{50}$ & 231.3 & 105.2 & 5583 & 716.8 \\
\hline R squared & 0.9389 & 0.9089 & 0.9617 & 0.9681 \\
\hline
\end{tabular}

\begin{tabular}{|l|l|l|}
\hline construct & $\begin{array}{l}\text { WholeS } \\
\text { DNA }\end{array}$ & $\begin{array}{l}\text { RBD } \\
\text { monomer }\end{array}$ \\
\hline $\mathrm{ID}_{50}$ & $<100$ & 5837 \\
\hline R squared & 0.8382 & 0.9446 \\
\hline
\end{tabular}



available under aCC-BY-NC 4.0 International license.

Figure 5

D

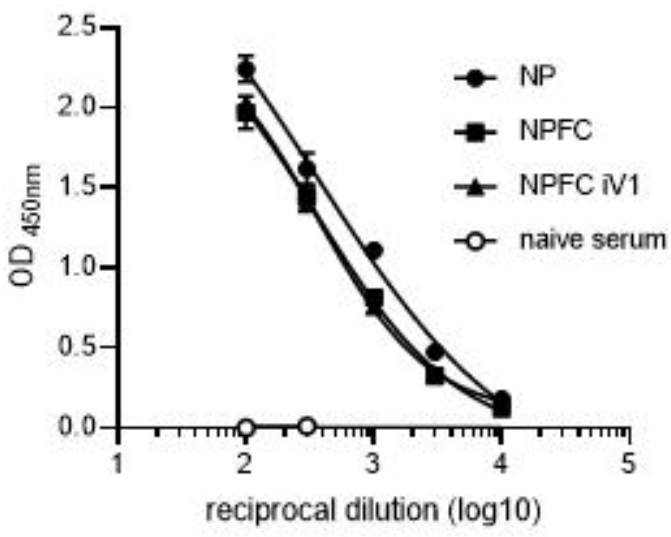

\begin{tabular}{|l|l|l|l|}
\hline & NP & NPFC & $\begin{array}{l}\text { NPFC } \\
\text { iV1 }\end{array}$ \\
\hline $\mathrm{EC}_{50}$ & 367 & 465 & 297 \\
\hline R squared & 0.9907 & 0.9951 & 0.9986 \\
\hline
\end{tabular}


Figure 6

A

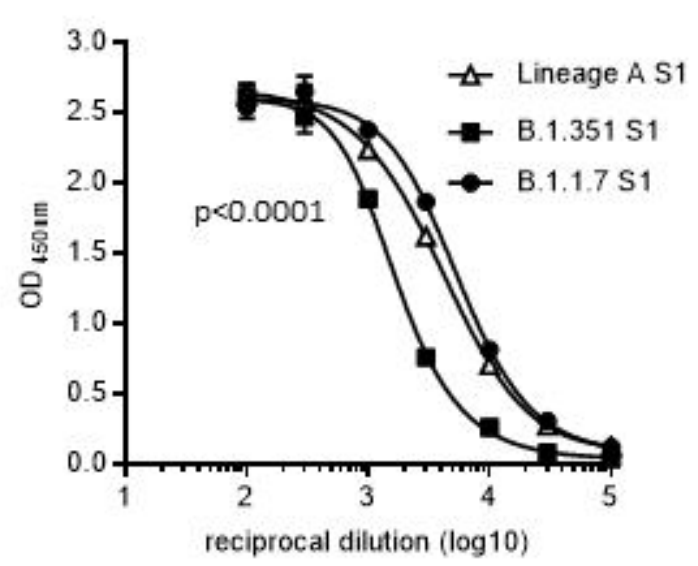

\begin{tabular}{|l|l|l|l|}
\hline & $\begin{array}{l}\text { Lineage } \\
\text { A S1 }\end{array}$ & $\begin{array}{l}\text { B.1.1.7 } \\
\text { S1 }\end{array}$ & $\begin{array}{l}\text { B.1.351 } \\
\text { S1 }\end{array}$ \\
\hline EC50 & 4022 & 5426 & 1696 \\
\hline R squared & 0.9978 & 0.9966 & 0.9974 \\
\hline
\end{tabular}

B

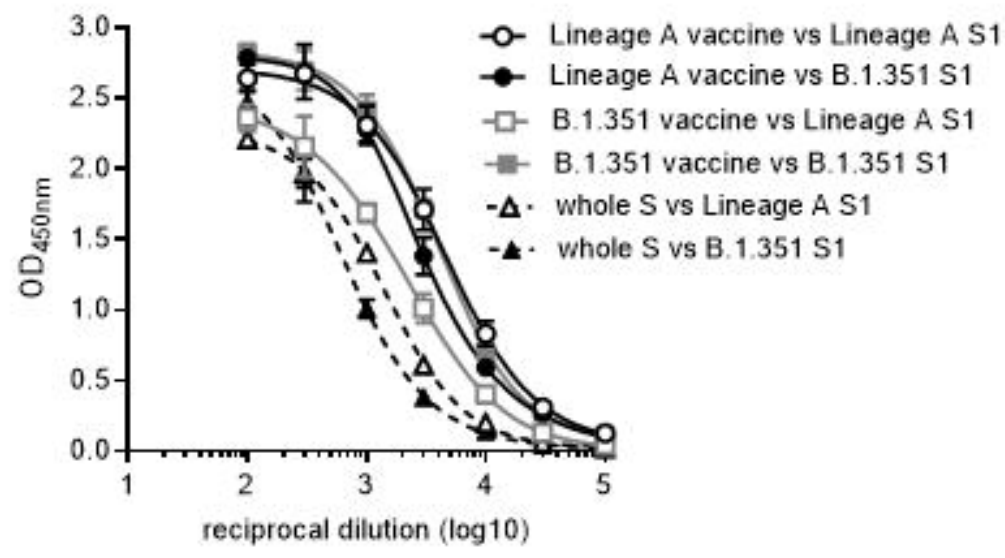

\begin{tabular}{|l|l|l|l|l|l|l|}
\hline \multirow{2}{*}{} & \multicolumn{2}{|l|}{ Lineage A vaccine } & \multicolumn{2}{l|}{ B.1.351 vaccine } & \multicolumn{2}{l|}{ Whole S } \\
\cline { 2 - 7 } & $\begin{array}{l}\text { Lineage } \\
\text { A S1 }\end{array}$ & $\begin{array}{l}\text { B.1.351 } \\
\text { S1 }\end{array}$ & $\begin{array}{l}\text { Lineage } \\
\text { A S1 }\end{array}$ & $\begin{array}{l}\text { B.1.351 } \\
\text { S1 }\end{array}$ & $\begin{array}{l}\text { Lineage } \\
\text { A S1 }\end{array}$ & $\begin{array}{l}\text { B.1.351 } \\
\text { S1 }\end{array}$ \\
\hline EC50 & 4664 & 2949 & 2086 & 3931 & 1389 & 644 \\
\hline R squared & 0.9935 & 0.9946 & 0.9913 & 0.9965 & 0.9974 & 0.9947 \\
\hline
\end{tabular}

C i

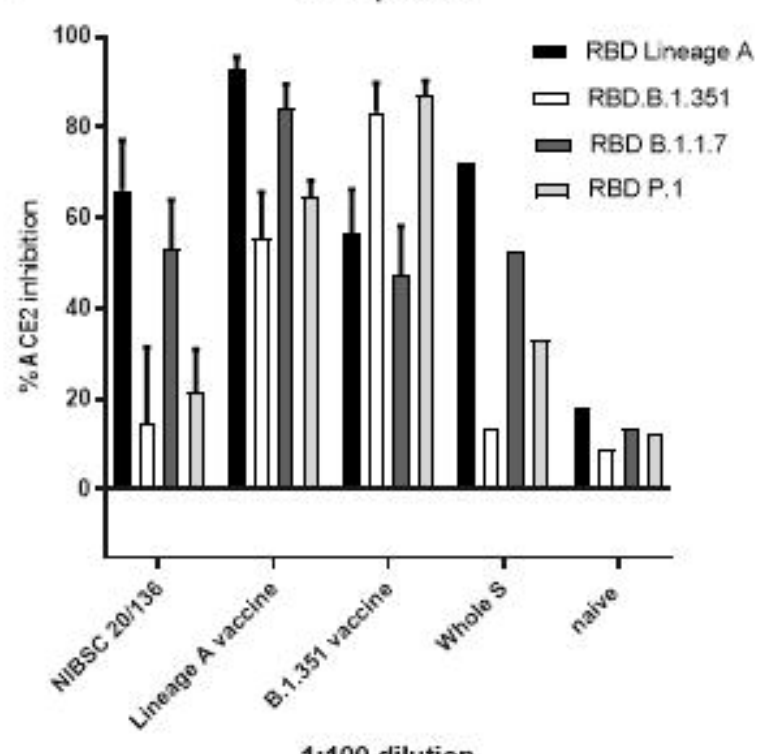

ii

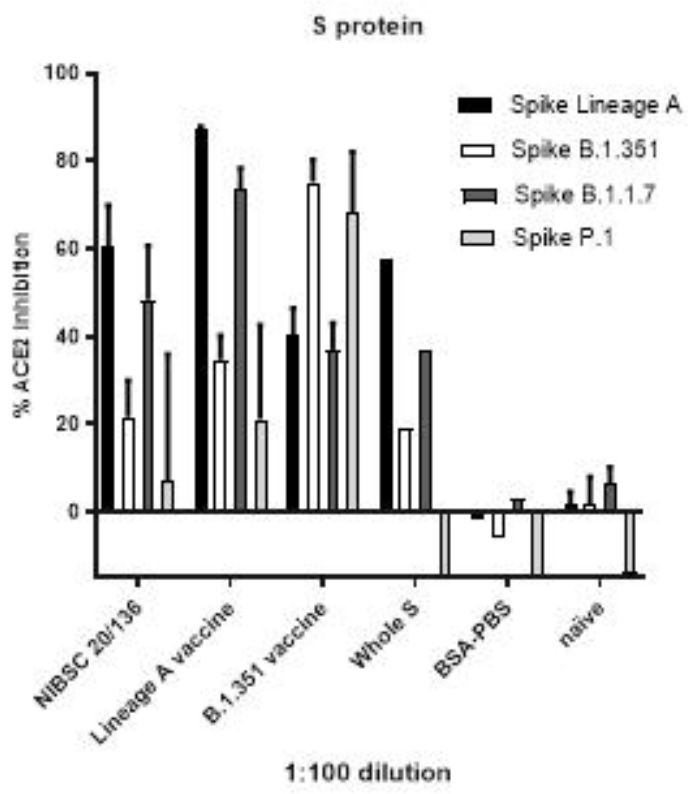


Figure 6

D

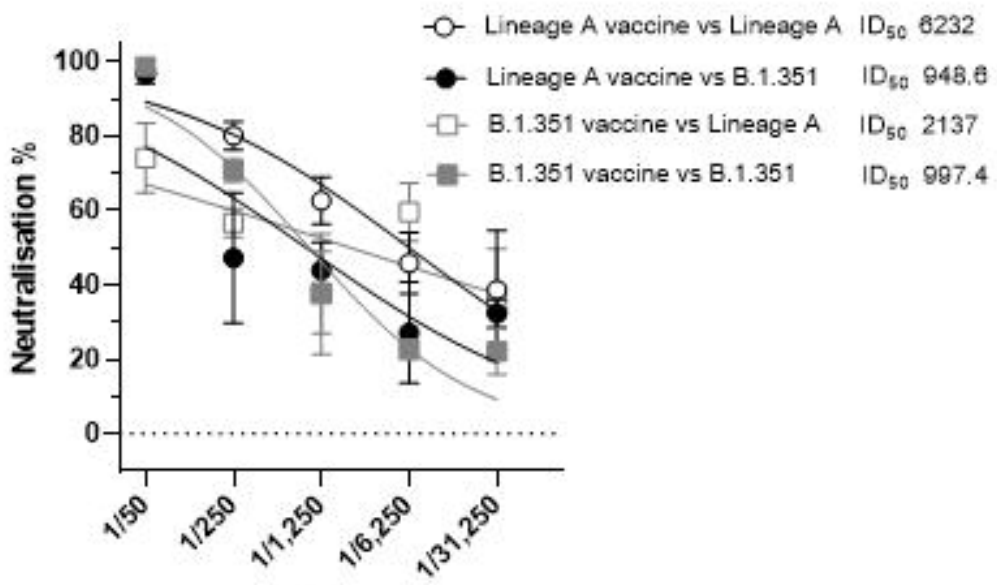

Dilution

$\mathrm{E}$

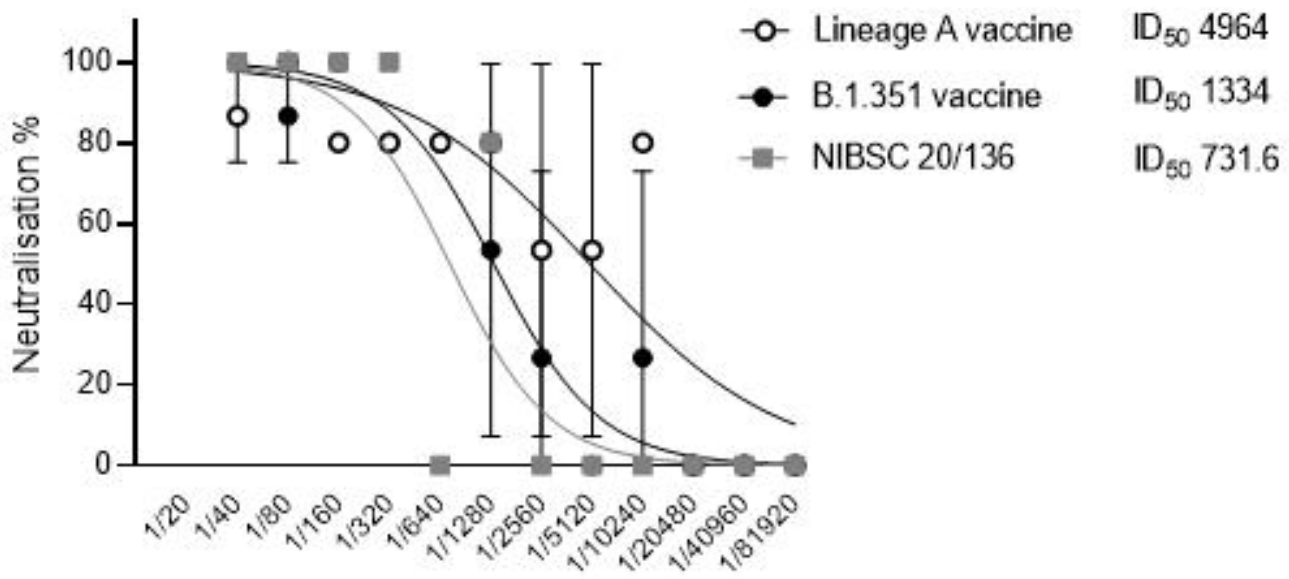

Serum dilution

F

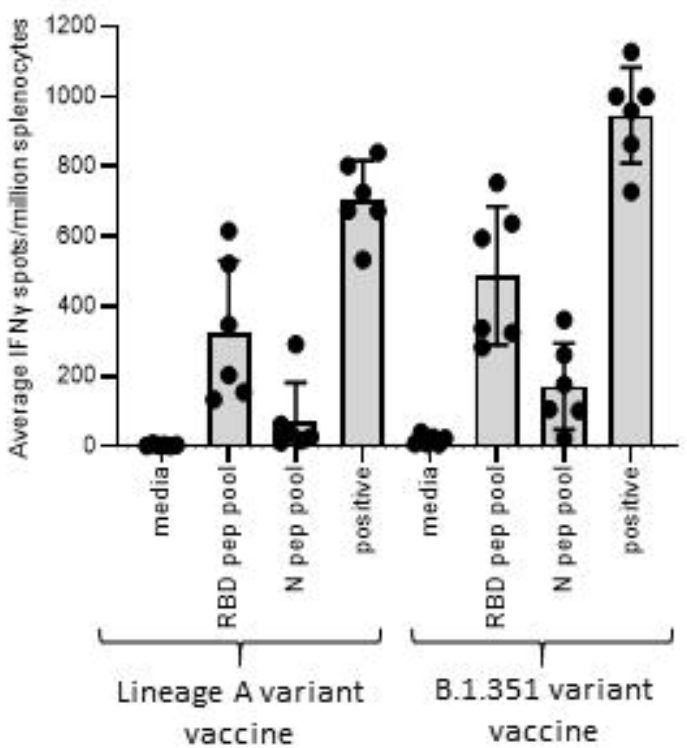

